\title{
Evidence of a wide gap between COVID-19 in humans and animal models: a systematic review
}

\author{
Salleh N. Ehaideb, Mashan L. Abdullah, Bisher Abuyassin and Abderrezak Bouchama* (D)
}

\begin{abstract}
Background: Animal models of COVID-19 have been rapidly reported after the start of the pandemic. We aimed to assess whether the newly created models reproduce the full spectrum of human COVID-19.

Methods: We searched the MEDLINE, as well as BioRxiv and MedRxiv preprint servers for original research published in English from January 1 to May 20, 2020. We used the search terms (COVID-19) OR (SARS-CoV-2) AND (animal models), (hamsters), (nonhuman primates), (macaques), (rodent), (mice), (rats), (ferrets), (rabbits), (cats), and (dogs). Inclusion criteria were the establishment of animal models of COVID-19 as an endpoint. Other inclusion criteria were assessment of prophylaxis, therapies, or vaccines, using animal models of COVID-19.

Result: Thirteen peer-reviewed studies and 14 preprints met the inclusion criteria. The animals used were nonhuman primates $(n=13)$, mice $(n=7)$, ferrets $(n=4)$, hamsters $(n=4)$, and cats $(n=1)$. All animals supported high viral replication in the upper and lower respiratory tract associated with mild clinical manifestations, lung pathology, and full recovery. Older animals displayed relatively more severe illness than the younger ones. No animal models developed hypoxemic respiratory failure, multiple organ dysfunction, culminating in death. All species elicited a specific lgG antibodies response to the spike proteins, which were protective against a second exposure. Transient systemic inflammation was observed occasionally in nonhuman primates, hamsters, and mice. Notably, none of the animals unveiled a cytokine storm or coagulopathy.

Conclusions: Most of the animal models of COVID-19 recapitulated mild pattern of human COVID-19 with full recovery phenotype. No severe illness associated with mortality was observed, suggesting a wide gap between COVID-19 in humans and animal models.
\end{abstract}

Keywords: COVID-19, SARS-CoV-2, Animal models, Review, Non-human primate, Rodent, Hamster, Ferrets

\section{Background}

Coronavirus disease 2019 (COVID-19) is a febrile respiratory illness due to a novel viral pathogen severe acute respiratory syndrome-coronavirus 2 (SARS-CoV-2) $[1,2]$. COVID-19 can progress to acute respiratory distress syndrome (ARDS), multiple organ dysfunction/failure

\footnotetext{
* Correspondence: bouchamaab@NGHA.MED.SA Experimental Medicine Department, King Abdullah International Medical
Research Center/King Saud bin Abdulaziz University for Health Sciences, King
Abdulaziz Medical City, Ministry of National Guard Health Affairs, Riyadh, Experimental Medicine Department, King Abdullah International Medical
Research Center/King Saud bin Abdulaziz University for Health Sciences, King
Abdulaziz Medical City, Ministry of National Guard Health Affairs, Riyadh, Experimental Medicine Department, King Abdullah International Medical
Research Center/King Saud bin Abdulaziz University for Health Sciences, King
Abdulaziz Medical City, Ministry of National Guard Health Affairs, Riyadh, Saudi Arabia
}

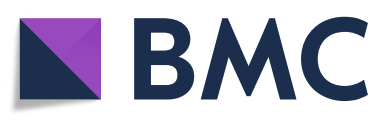

(c) The Author(s). 2020 Open Access This article is licensed under a Creative Commons Attribution 4.0 International License, which permits use, sharing, adaptation, distribution and reproduction in any medium or format, as long as you give appropriate credit to the original author(s) and the source, provide a link to the Creative Commons licence, and indicate if changes were made. The images or other third party material in this article are included in the article's Creative Commons licence, unless indicated otherwise in a credit line to the material. If material is not included in the article's Creative Commons licence and your intended use is not permitted by statutory regulation or exceeds the permitted use, you will need to obtain permission directly from the copyright holder. To view a copy of this licence, visit http://creativecommons.org/licenses/by/4.0/ The Creative Commons Public Domain Dedication waiver (http://creativecommons.org/publicdomain/zero/1.0/) applies to the data made available in this article, unless otherwise stated in a credit line to the data.

(MOSD) including central nervous system alteration, acute kidney injury, cardiovascular failure, liver injury, and coagulopathy culminating in death [2-9].

SARS-CoV-2 is a beta coronavirus that binds with a high affinity to angiotensin-converting enzyme (ACE) 2 receptor and uses the transmembrane serine protease (TMPRSS) 2 as co-receptor to gain entry to cells [1012]. ACE 2 and TMPRSS 2 are co-expressed in many tissues and organs, particularly the nasal epithelial cells and alveolar type II cells of the lungs, which may explain 
in part the easy transmission from person-to-person, and its dissemination within the body in severe and fatal cases [11-18]. Accordingly, SARS-CoV-2-induced COVID-19 has led to a pandemic that overwhelmed the capacity of most national health systems, resulting in a global health crisis [19]. So far, an estimated 11,280 million persons in 188 countries were infected, of which 531,000 died [20].

The clinical spectrum of COVID-19 is complex and has been categorized as mild, severe, and critical, representing 81,14 , and $5 \%[2,3]$. The mild pattern comprises patients with either no signs and symptoms or fever and radiological evidence of pneumonia [3]. The severe pattern manifests as rapidly progressive hypoxemic pneumonia involving more than half of the lung with a full recovery phenotype $[2,3]$. The critical pattern consists of ARDS requiring respiratory assistance and MOSD that result in death in approximately half of the patients $[2,3,7,21]$. Mortality was associated with host factors such as old age, comorbidities, and immune response [4].

Viral and immunopathological studies revealed distinct patterns between mild and severe or critical forms of COVID-19 [4, 5, 9, 21-27]. Both severe and critically ill patients displayed higher viral load in the upper respiratory tract than mild cases, together with delayed clearance overtime $[21,22]$. Likewise, they presented with lymphopenia due to a decrease in $\mathrm{CD} 4+$ and $\mathrm{CD} 8+\mathrm{T}$ cells, as well as $\mathrm{T}$ cell exhaustion accompanied by a marked inflammatory response [5, 9, 24-27]. Pro- and anti-inflammatory cytokines and chemokine concentrations were increased systemically and locally in the lung and correlated with severity $[5,9,24]$. In contrast, in the mild illness, the lymphocyte count was normal, with no or minimal inflammatory response [5, 23]. Together, these suggest that the viral load and dynamic together with the host inflammatory response may play a pathogenic role.

Clinical and post-mortem studies of fatal cases of COVID-19 demonstrated major alteration of coagulation and fibrinolysis $[17,18]$. This was associated with widespread thrombosis of small and large vessels, particularly of the pulmonary circulation contributing to death in a third of patients $[8,28-33]$. These observations suggest that dysregulated coagulation may be an important mechanism of COVID-19 morbidity and mortality [34].

In this context, animal models appear crucial to a better understanding of the complex biology of COVID-19. Animal models of SARS-CoV-2-induced COVID-19 have been rapidly reported since the start of the pandemic [35]. However, whether they express the full phenotype of COVID-19, particularly the severe and critical patterns associated with lethality, remains to be determined. In this systematic review, we examined whether the newly created animal models reproduce the phenotype of human COVID-19. Moreover, we examined the knowledge generated by these models of COVID-19 including viral dynamic and transmission, pathogenesis, and testing of therapy and vaccines.

\section{Methods}

\section{Search strategy and selection criteria}

We conducted a systematic review according to the Preferred Reporting Items for Systematic Reviews and Meta-analysis (PRISMA) statement [36] to identify studies describing the creation of an animal model of COVID-19 as an endpoint (Table 1 and Additional file 1). Additional file 1 shows the data extraction and appraisal approach as well as the selected outcome.

\section{Results}

The systematic search identified 101 studies and 326 preprints, of which 400 articles were excluded because they were reviews, non-original articles, unrelated to the COVID-19 infection, or experimental animals that do not support SARS-CoV-2 replication such as pigs, ducks, and chickens (Fig. 1 and Additional file 2). Additional file 2 displays all the excluded studies and the rationale for their exclusion. Thirteen peer-reviewed studies and 14 preprints were included in the analysis.

The studies used nonhuman primates $(n=13)$ [3749], mice $(n=7)$ [50-56], hamsters $(n=4)$ [56-59], ferrets $(n=4)$ [60-63], cats, and dogs $(n=1)$ [63] (Tables 2, 3,4 , and 5). Male and female, as well as young and old, were included but with no associated comorbidities. The aims were to investigate the pathogenesis of COVID-19 $(n=15)$, testing drugs and vaccines $(n=14)$, the host

Table 1 Search strategy and selection criteria

We searched the MEDLINE, as well as BioRxiv and MedRxiv preprint servers for original research describing or using an animal model of SARS-CoV-2 induced COVID published in English from January 1, 2020, to May 20, 2020. We used the search terms (COVID-19) OR (SARS-CoV-2) AND, (animal models), (hamsters), (nonhuman primates), (macaques), (rodent), (mice), (rats), (ferrets), (rabbits), (cats), and (dogs). The preprint servers were included in the search as the field of COVID-19 is developing quickly. Inclusion criteria were the establishment of animal models of COVID-19 as an endpoint. Other inclusion criteria were assessment of prophylaxis, therapies, or vaccines, using animal models of COVID-19. Exclusion criteria consisted of reviews, non-original articles, and unrelated to the COVID-19 infection or experimental animals that do not support SARS-CoV-2 replication. 101 studies and 326 preprints were screened of which 13 peer-reviewed studies and 14 preprints were included in the final analysis (Fig. 1). The variables extracted were the population type, study aim, the virus strain used, clinical response, pathology, viral replication, and host response as well as the effects of prophylaxis, drugs, or vaccines. The outcomes were organized according to species and categorized into phenotype (signs or symptoms; histopathology, timecourse of the illness and outcome), viral (titer in each tissue organ, detection methods, duration of positivity), and host response (dynamic of seroconversion, inflammatory, and hemostatic markers), therapy, and vaccine (efficacy and safety) 


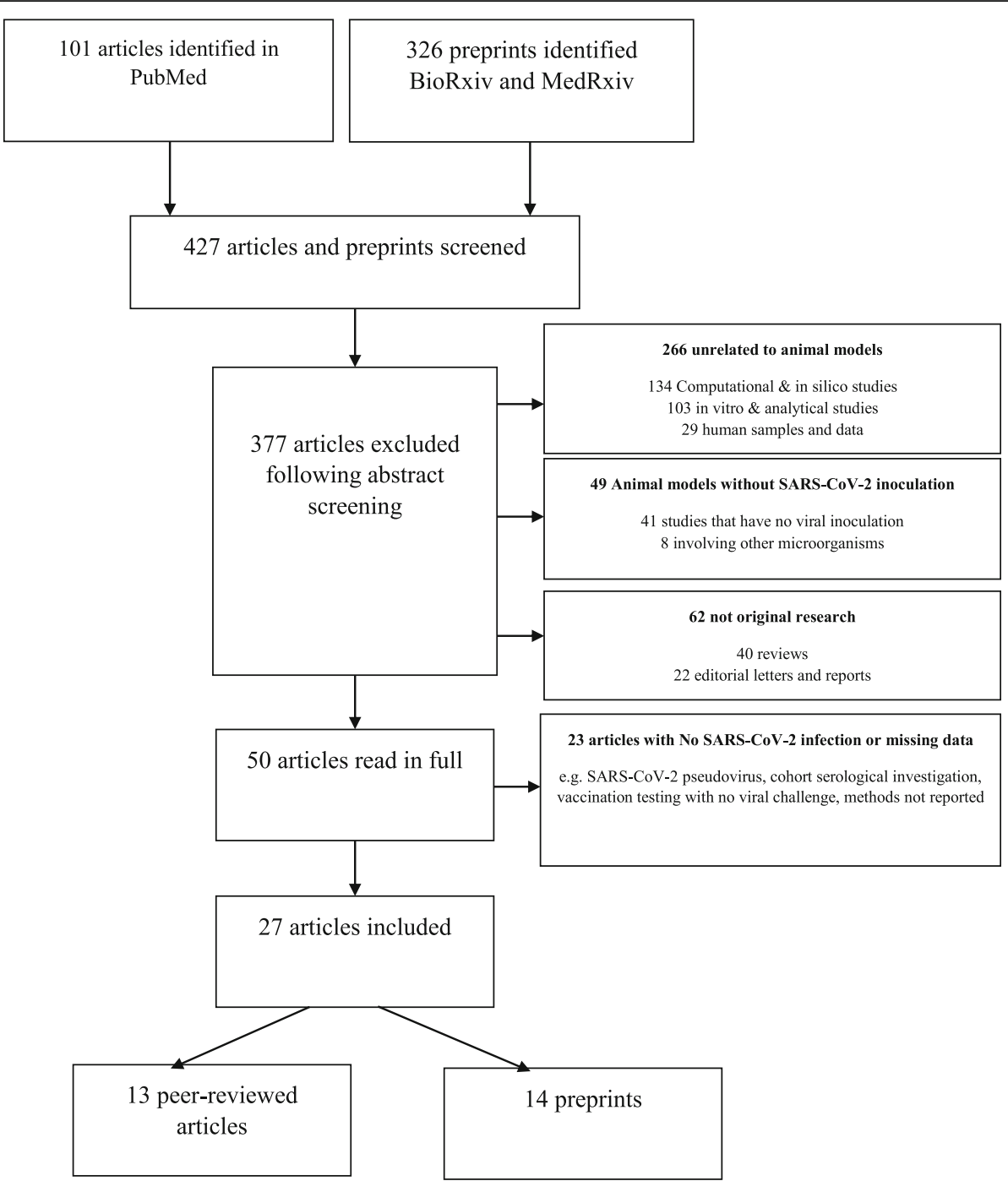

Fig. 1 Flow diagram illustrating the process of study selection. A systematic review was conducted according to the Preferred Reporting Items for Systematic Reviews and Meta-analysis (PRISMA). *Flow diagram

immune response $(n=6)$, and the virus dynamic and transmission $(n=4)$ (Tables $2,3,4$, and 5).

All the experimental animals were inoculated with SARS-CoV-2 with various strains, doses, and route of administration that differed across studies (Tables 2, 3, 4 , and 5). Likewise, the time-point for tissue collection and pathological assessment were variables. These together precluded any comparisons between the animal models either intra-species or inter-species.

\section{Nonhuman primate models Viral model}

Rhesus macaques $(n=10)$ [37-46], cynomolgus $(n=3)$ [46-48], and African Green model $(n=1)$ [49] and common marmoset $(n=1)$ [46] were assessed as models for COVID-19 (Table 2). SARS-CoV-2 strains, dose, and route of inoculation were different across studies.
Different doses of virus inoculum were compared in a single study and showed that viral load in the upper and lower respiratory tract, fever, weight loss, respiratory distress, and mortality were comparable regardless of the doses except for mild transient neutropenia and lymphopenia in the high dose group [43]. In contrast, the route of administration resulted in different pathological response as the intratracheal route elicited severe interstitial pneumonia, as compared with mild interstitial pneumonia and no pneumonia from the intraconjunctival and intragastric routes, respectively [45]. The animals were euthanized at different time-points post-inoculation ranging from 3 to 33 days.

\section{Phenotype}

The animals displayed variable clinical manifestations from none to fever, altered respiratory patterns, and 
Table 2 Summary of studies using nonhuman primate models of COVID-19

\begin{tabular}{|c|c|c|c|c|c|c|c|c|}
\hline Species (ref) & $\begin{array}{l}\text { Number } \\
\text { age } \\
\text { (gender) }\end{array}$ & $\begin{array}{l}\text { Virus strain } \\
\text { dose* } \\
\text { (inoculation } \\
\text { route) } \dagger\end{array}$ & $\begin{array}{l}\text { Clinical } \\
\text { signs \& } \\
\text { observation } \\
\text { duration } \\
\text { (DPI) § }\end{array}$ & $\begin{array}{l}\text { Viral replication } \neq \\
\text { (DPI) }\end{array}$ & $\begin{array}{l}\text { Pathology \& } \\
\text { sacrificing date } \\
\text { (DPI) }\end{array}$ & $\begin{array}{l}\text { Immune } \\
\text { response }\end{array}$ & $\begin{array}{l}\text { Seroconversion } \\
\text { (DPI) }\end{array}$ & $\begin{array}{l}\text { Outcome } \\
\text { measures }\end{array}$ \\
\hline \multirow[t]{2}{*}{$\begin{array}{l}\text { Rhesus } \\
\text { macaques }\end{array}$} & $n=8$ & $\begin{array}{l}\text { SARS-CoV-2 } \\
\text { nCoV-WA1-2020 }\end{array}$ & Fever & $\begin{array}{l}\text { Nose, oropharynx, } \\
\text { lung }\end{array}$ & Anemia & \multirow{3}{*}{$\begin{array}{l}\text { At } 1 \text { dpi only, } \\
\text { significant } \\
\text { increases in } \\
\text { IL1ra, IL6, IL10, } \\
\text { IL15, MCP-1, } \\
\text { MIP-1b }\end{array}$} & \multirow{8}{*}{$\begin{array}{l}\text { lgG antibody } \\
\text { anti-spike protein } \\
\text { (10) }\end{array}$} & \multirow[t]{8}{*}{$\begin{array}{l}\text { Pathogenesis } \\
\text { of COVID-19 }\end{array}$} \\
\hline & Adults & & Weight loss & Rectum (1) & $\begin{array}{l}\text { Mild to moderate, } \\
\text { interstitial } \\
\text { pneumonia, }\end{array}$ & & & \\
\hline \multirow[t]{6}{*}{$\begin{array}{l}\text { Munster et al. } \\
\text { (2020) [37] }\end{array}$} & \multirow[t]{6}{*}{$(M / F)$} & \multirow[t]{6}{*}{$\begin{array}{l}4 \times 10^{5} \mathrm{TCID}_{50} \\
(\mathrm{IT}, \mathrm{IN}, \mathrm{PO})\end{array}$} & $\begin{array}{l}\text { Dyspnea } \\
\text { Tachypnea }\end{array}$ & & Edema & & & \\
\hline & & & Piloerection & & $\begin{array}{l}\text { Hyaline } \\
\text { membranes } \\
\text { formation }\end{array}$ & \multirow[t]{5}{*}{$\begin{array}{l}\text { At } 3 \text { dpi } \\
\text { decrease in } \\
\text { TGFa }\end{array}$} & & \\
\hline & & & $\begin{array}{l}\text { Reduced } \\
\text { appetite }\end{array}$ & & $\begin{array}{l}\text { Hyperplasia type } \\
\text { II pneumocytes }\end{array}$ & & & \\
\hline & & & $\begin{array}{l}\text { Hunched } \\
\text { posture }\end{array}$ & & \multirow{3}{*}{$\begin{array}{l}\text { Swollen } \\
\text { mediastinal } \\
\text { lymph nodes ( } 3 \text {, } \\
4,21)\end{array}$} & & & \\
\hline & & & $\begin{array}{l}\text { Pale } \\
\text { appearance }\end{array}$ & & & & & \\
\hline & & & $\begin{array}{l}\text { Dehydration } \\
\text { (21) }\end{array}$ & & & & & \\
\hline \multirow[t]{2}{*}{$\begin{array}{l}\text { Rhesus } \\
\text { macaques }\end{array}$} & $n=3$ & $\begin{array}{l}\text { BetaCoV/ } \\
\text { Wuhan/IVDC-HB- } \\
01 / 2020\end{array}$ & Weight loss & $\begin{array}{l}\text { Nose, oropharynx, } \\
\text { lung }\end{array}$ & $\begin{array}{l}\text { Interstitial } \\
\text { pneumonia }\end{array}$ & \multirow[t]{4}{*}{$\begin{array}{l}\text { Decreased } \\
\text { CD4+ T and } \\
\text { CD8+ T cells in } \\
\text { young and old. }\end{array}$} & \multirow[t]{4}{*}{$\begin{array}{l}\text { IgG antibody } \\
\text { anti- SARS-CoV-2 } \\
\text { (14) }\end{array}$} & \multirow[t]{4}{*}{$\begin{array}{l}\text { Pathogenesis } \\
\text { of COVID-19 } \\
\text { in aging } \\
\text { animals }\end{array}$} \\
\hline & $3-5$ years & & Asthenia & $\begin{array}{l}\text { Rectum, alveolar } \\
\text { epithelia }\end{array}$ & Inflammation & & & \\
\hline \multirow[t]{2}{*}{$\begin{array}{l}\text { Yu et al. (2020) } \\
\text { [38] }\end{array}$} & $n=2$ & $\begin{array}{l}1 \times 10^{6} \mathrm{TCID}_{50} \\
(\mathrm{IT})\end{array}$ & $\begin{array}{l}\text { More severe } \\
\text { in old than } \\
\text { young (14) }\end{array}$ & Macrophages (3) & Edema & & & \\
\hline & $\begin{array}{l}15 \text { years } \\
(N A) \|\end{array}$ & & & $\begin{array}{l}\text { Higher replication in } \\
\text { old than young }\end{array}$ & $\begin{array}{l}\text { More severe in } \\
\text { old than young } \\
\text { (7) }\end{array}$ & & & \\
\hline \multirow{2}{*}{$\begin{array}{l}\text { Rhesus } \\
\text { macaques }\end{array}$} & \multirow{2}{*}{$\begin{array}{l}n=4 \text { per } \\
\text { group (6 } \\
\text { vaccinated } \\
\text { groups) }\end{array}$} & DNA vaccine $e^{* *}$ & \multirow[t]{5}{*}{ NAll (14) } & \multirow{3}{*}{$\begin{array}{l}\text { Lowest BAL levels of } \\
\text { viral RNA with full- } \\
\text { length S protein en- } \\
\text { coding vaccine }\end{array}$} & \multirow[t]{3}{*}{ NA } & \multirow{2}{*}{$\begin{array}{l}\text { Upregulation } \\
\text { IFN- } \gamma \text { antipep- } \\
\text { tide spike } \\
\text { proteins. }\end{array}$} & \multirow{3}{*}{$\begin{array}{l}\text { IgG antibody } \\
\text { anti- SARS-CoV-2 } \\
\text { (day14 post- } \\
\text { vaccination) }\end{array}$} & \multirow{5}{*}{$\begin{array}{l}\text { Evaluation of } \\
\text { candidate } \\
\text { DNA vaccine }\end{array}$} \\
\hline & & $\begin{array}{l}\text { IM at week } 0 \\
\text { and week } 3\end{array}$ & & & & & & \\
\hline \multirow[t]{3}{*}{$\begin{array}{l}\text { Yu et al. (2020) } \\
\text { [39] }\end{array}$} & $\begin{array}{l}6-12 \text { years } \\
(M / F)\end{array}$ & $\begin{array}{l}1.1 \times 10^{4} \mathrm{PFU}(\mathrm{IN} \\
\text { and IT) (day } 21 \\
\text { post-vaccine) }\end{array}$ & & & & $\begin{array}{l}\mathrm{S} 1 \text { and } \mathrm{RBD} \\
\text { lower response } \\
\text { than other } \\
\text { variant Spike } \\
\text { proteins }^{* *}\end{array}$ & & \\
\hline & $\begin{array}{l}n=10 \\
\text { sham } \\
\text { control }\end{array}$ & $\begin{array}{l}1.1 \times 10^{4} \mathrm{PFU}(\mathrm{IN} \\
\text { and } \mathrm{IT})\end{array}$ & & $\begin{array}{l}\text { High BAL levels of } \\
\text { viral RNA }\end{array}$ & NA & \multirow{2}{*}{$\begin{array}{l}\text { Anamnestic } \\
\text { humoral and } \\
\text { cellular } \\
\text { immune } \\
\text { responses } \\
\text { including IFN- } \gamma \\
\text { ELISPOT } \\
\text { responses }\end{array}$} & \multirow[t]{2}{*}{ NA } & \\
\hline & $\begin{array}{l}6-12 \text { years } \\
(\mathrm{M} / \mathrm{F})\end{array}$ & & & & & & & \\
\hline \multirow[t]{3}{*}{$\begin{array}{l}\text { Rhesus } \\
\text { macaques }\end{array}$} & $\begin{array}{l}n=6 \\
\text { vaccine }\end{array}$ & $\begin{array}{l}2.5 \times 10^{10} \\
\text { ChAdOx1 nCoV- } \\
19 \text { (IM) }\end{array}$ & $\begin{array}{l}\text { Tachypnea } \\
(3 / 6), \\
\text { dyspnea (2/ } \\
6),\end{array}$ & Nose, BAL $(2 / 6)$ & NO & \multirow[t]{2}{*}{$\begin{array}{l}\text { Upregulation of } \\
\text { IFN- }-\gamma(1)\end{array}$} & \multirow[t]{3}{*}{$\begin{array}{l}\text { IgG antibody } \\
\text { anti-SARS-CoV-2 } \\
\text { spike protein } \\
\text { (day } 14 \text { post- } \\
\text { vaccination) }\end{array}$} & \multirow[t]{3}{*}{$\begin{array}{l}\text { Evaluation of } \\
\text { DNA vaccine }\end{array}$} \\
\hline & $M / F$ & $\begin{array}{l}\text { SARS-CoV-2 } \\
\text { nCoV-WA1-2020 }\end{array}$ & $\begin{array}{l}\text { Ruffled fur } \\
(1 / 6)(7)\end{array}$ & $\begin{array}{l}\text { Lung (very low), } \\
\text { oropharynx, } \\
\text { mediastinal, } \\
\text { duodenum (3) }\end{array}$ & & & & \\
\hline & & $\begin{array}{l}2.6 \times 10^{6} \mathrm{TCID}_{50} \\
(\mathrm{IT}, \mathrm{IN}, \mathrm{PO}, \mathrm{CJ}) \\
\text { (day } 28 \text { post- } \\
\text { vaccine) }\end{array}$ & & $\begin{array}{l}\text { No BAL subgenomic } \\
\text { viral RNA }\end{array}$ & & $\begin{array}{l}\text { No difference } \\
\text { in TNF-a, IL-2, } \\
\text { IL-4, IL-6, and } \\
\text { IL-10 vaccine }\end{array}$ & & \\
\hline
\end{tabular}


Table 2 Summary of studies using nonhuman primate models of COVID-19 (Continued)

\begin{tabular}{|c|c|c|c|c|c|c|c|c|}
\hline Species (ref) & $\begin{array}{l}\text { Number } \\
\text { age } \\
\text { (gender) }\end{array}$ & $\begin{array}{l}\text { Virus strain } \\
\text { dose* } \\
\text { (inoculation } \\
\text { route)t }\end{array}$ & $\begin{array}{l}\text { Clinical } \\
\text { signs \& } \\
\text { observation } \\
\text { duration } \\
\text { (DPI) § }\end{array}$ & $\begin{array}{l}\text { Viral replication } \neq \\
\text { (DPI) }\end{array}$ & $\begin{array}{l}\text { Pathology \& } \\
\text { sacrificing date } \\
\text { (DPI) }\end{array}$ & $\begin{array}{l}\text { Immune } \\
\text { response }\end{array}$ & $\begin{array}{l}\text { Seroconversion } \\
\text { (DPI) }\end{array}$ & $\begin{array}{l}\text { Outcome } \\
\text { measures }\end{array}$ \\
\hline & & & & & & vs. control & & \\
\hline \multirow{5}{*}{$\begin{array}{l}\text { Van } \\
\text { Doremalen } \\
\text { et al. (2020) } \\
{[40]}\end{array}$} & \multirow[t]{2}{*}{$\begin{array}{l}n=3 \\
\text { control' }\end{array}$} & \multirow{2}{*}{$\begin{array}{l}\text { Vaccinated with } \\
2.5 \times 10^{10} \\
\text { ChAdOx1 GFP } \\
(\text { IM) }\end{array}$} & \multirow{2}{*}{$\begin{array}{l}\text { Tachypnea } \\
\text { (3/3) Ruffled } \\
\text { fur (2/3) } \\
\text { Diarrhea (1/ } \\
\text { 3) Pale } \\
\text { appearance } \\
\text { (1/3) }\end{array}$} & \multirow{2}{*}{$\begin{array}{l}\text { BAL, nasal swabs, } \\
\text { lung, cervical, } \\
\text { mediastinal lymph } \\
\text { nodes, duodenum, } \\
\text { urinary bladder }\end{array}$} & $\begin{array}{l}\text { Interstitial } \\
\text { pneumonia (2 of } \\
3 \text { ) }\end{array}$ & \multirow[t]{5}{*}{$\begin{array}{l}\text { TNF-a, IL-2, IL-4, } \\
\text { IL-6, and IL-10 }\end{array}$} & \multirow[t]{5}{*}{ NA } & \\
\hline & & & & & $\begin{array}{l}\text { Thickening of } \\
\text { alveolar septae }\end{array}$ & & & \\
\hline & \multirow[t]{3}{*}{$M / F^{\prime}$} & & $\begin{array}{l}\text { Red nose (1/ } \\
\text { 3) }\end{array}$ & & Edema & & & \\
\hline & & $\begin{array}{l}\text { SARS-CoV-2 } \\
\text { nCoV-WA1-2020 }\end{array}$ & & $\begin{array}{l}\text { BAL subgenomic } \\
\text { viral RNA }(3,5)\end{array}$ & $\begin{array}{l}\text { Hyperplasia type I } \\
\& \text { II pneumocytes } \\
\text { syncytial cells }\end{array}$ & & & \\
\hline & & $\begin{array}{l}2.6 \times 10^{6} \mathrm{TCID}_{50} \\
(\mathrm{IT}, \mathrm{IN}, \mathrm{PO}, \mathrm{CJ}) \\
\text { (day } 28 \text { post- } \\
\text { vaccine) }\end{array}$ & & & $\begin{array}{l}\text { No extra } \\
\text { pulmonary injury }\end{array}$ & & & \\
\hline \multirow[t]{3}{*}{$\begin{array}{l}\text { Rhesus } \\
\text { macaques }\end{array}$} & $\begin{array}{l}n=4 \text { per } \\
\text { vaccine } \\
\text { group }\end{array}$ & $\begin{array}{l}\text { PiCoVacc } 6 \mu \mathrm{g} / \\
\text { dose (high) or } \\
3 \mu \mathrm{g} / \text { dose (low) } \\
\text { at } 0,7 \text {, and } 14 \\
\text { days (IM) }\end{array}$ & \multirow[t]{3}{*}{ NA } & \multirow[t]{3}{*}{$\begin{array}{l}\text { Pharyngeal, anal, and } \\
\text { pulmonary (3) }\end{array}$} & \multirow[t]{3}{*}{$\begin{array}{l}\text { Mild and focal } \\
\text { histopathological } \\
\text { changes both } \\
\text { lower lobes }\end{array}$} & \multirow[t]{3}{*}{$\begin{array}{l}\text { No differences } \\
\text { CD3+, CD4+, } \\
\text { CD8+, TNF-a, } \\
\text { IFN- } \text { I I I-2, IL-4, } \text { IL-5, IL-6 vac- } \\
\text { cine vs. control }\end{array}$} & \multirow[t]{7}{*}{$\begin{array}{l}\text { IgG antibody } \\
\text { anti-SARS-CoV-2 } \\
\text { (day } 14 \text { post- } \\
\text { vaccination) }\end{array}$} & \multirow[t]{7}{*}{$\begin{array}{l}\text { Evaluation of } \\
\text { an } \\
\text { inactivated } \\
\text { vaccine }\end{array}$} \\
\hline & \multirow[t]{2}{*}{$\begin{array}{l}3-4 \text { years } \\
(\mathrm{M} / \mathrm{F})\end{array}$} & $\begin{array}{l}\text { SARS-CoV-2-2/ } \\
\text { human/CHN/ } \\
\text { CN1/2020 }\end{array}$ & & & & & & \\
\hline & & $\begin{array}{l}1 \times 10^{6} \mathrm{TCID}_{50} \\
\text { (IT) (day } 22 \text { post- } \\
\text { vaccine) }\end{array}$ & & & & & & \\
\hline \multirow[t]{4}{*}{$\begin{array}{l}\text { Gao et al. } \\
\text { (2020) [41] }\end{array}$} & $\begin{array}{l}n=4 \\
\text { control }\end{array}$ & $\begin{array}{l}\text { Vaccinated with } \\
\mathrm{Al}(\mathrm{OH}) 3 \\
\text { adjuvant (sham) } \\
\text { or physiological } \\
\text { saline (control) } \\
\text { at } 0,7 \text {, and } 14 \\
\text { days }\end{array}$ & \multirow[t]{4}{*}{ NA (7) } & \multirow[t]{4}{*}{$\begin{array}{l}\text { Oropharynx, crissum, } \\
\text { lung, rectum (3) }\end{array}$} & \multirow[t]{4}{*}{$\begin{array}{l}\text { Severe interstitial } \\
\text { pneumonia }\end{array}$} & \multirow[t]{4}{*}{$\begin{array}{l}\text { CD3+, CD4+, } \\
\text { CD8+, TNF-a, } \\
\text { IFN- } \gamma, \text { IL-2, IL-4, } \\
\text { IL-5, IL-6 }\end{array}$} & & \\
\hline & \multirow{3}{*}{$\begin{array}{l}3-4 \text { years } \\
(\mathrm{M} / \mathrm{F})\end{array}$} & IM & & & & & & \\
\hline & & $\begin{array}{l}\text { SARS-CoV-2-2/ } \\
\text { human/CHN/ } \\
\text { CN1/2020 }\end{array}$ & & & & & & \\
\hline & & $\begin{array}{l}1 \times 10^{6} \mathrm{TCID}_{50} \\
(\mathrm{IT}) \\
\text { ( } 22 \text { days post- } \\
\text { vaccine) }\end{array}$ & & & & & & \\
\hline \multirow[t]{3}{*}{$\begin{array}{l}\text { Rhesus } \\
\text { macaques }\end{array}$} & $n=6$ & $\begin{array}{l}\text { SARS-CoV-2 } \\
\text { nCoV-WA1-2020 }\end{array}$ & $\begin{array}{l}\text { Dyspnea (1/ } \\
\text { 6) (7) }\end{array}$ & $\begin{array}{l}\text { Nose, oropharynx, } \\
\text { lung (1) }\end{array}$ & \multirow{2}{*}{$\begin{array}{l}\text { Minimal } \\
\text { interstitial } \\
\text { pneumonia } \\
\text { subpleural spaces } \\
(3 / 6)(7)(7)\end{array}$} & \multirow[t]{3}{*}{ NA } & \multirow[t]{3}{*}{ NA } & \multirow{5}{*}{$\begin{array}{l}\text { Testing of } \\
\text { antiviral } \\
\text { therapy }\end{array}$} \\
\hline & Remdesivir & & & Low BAL titers (1) & & & & \\
\hline & $(M / F)$ & $\begin{array}{l}2.6 \times 10^{6} \mathrm{TCID}_{50} \\
(\mathrm{IT}, \mathrm{IN}, \mathrm{OC}, \mathrm{PO})\end{array}$ & & No virus in BAL (3) & $\begin{array}{l}\text { No extra } \\
\text { pulmonary injury }\end{array}$ & & & \\
\hline \multirow[t]{2}{*}{$\begin{array}{l}\text { Williamson, } \\
\text { B.N. et al. } \\
\text { (2020) [42] }\end{array}$} & $\begin{array}{l}n=6 \\
\text { control }\end{array}$ & Vehicle solution & $\begin{array}{l}\text { Tachypnea, } \\
\text { dyspnea }\end{array}$ & $\begin{array}{l}\text { Nose, oropharynx, } \\
\text { lung, and BAL (1) }\end{array}$ & $\begin{array}{l}\text { Multifocal, mild } \\
\text { to moderate, } \\
\text { interstitial } \\
\text { pneumonia (7) }\end{array}$ & \multirow[t]{2}{*}{ NA } & \multirow[t]{2}{*}{ NA } & \\
\hline & $(M / F)$ & $\begin{array}{l}\text { SARS-CoV-2 } \\
\text { CoV-WA1-2020 }\end{array}$ & & & $\begin{array}{l}\text { No extra } \\
\text { pulmonary injury }\end{array}$ & & & \\
\hline
\end{tabular}


Table 2 Summary of studies using nonhuman primate models of COVID-19 (Continued)

\begin{tabular}{|c|c|c|c|c|c|c|c|c|}
\hline Species (ref) & $\begin{array}{l}\text { Number } \\
\text { age } \\
\text { (gender) }\end{array}$ & $\begin{array}{l}\text { Virus strain } \\
\text { dose* } \\
\text { (inoculation } \\
\text { route) } \dagger\end{array}$ & $\begin{array}{l}\text { Clinical } \\
\text { signs \& } \\
\text { observation } \\
\text { duration } \\
\text { (DPI) § }\end{array}$ & $\begin{array}{l}\text { Viral replication‡ } \\
\text { (DPI) }\end{array}$ & $\begin{array}{l}\text { Pathology \& } \\
\text { sacrificing date } \\
\text { (DPI) }\end{array}$ & $\begin{array}{l}\text { Immune } \\
\text { response }\end{array}$ & $\begin{array}{l}\text { Seroconversion } \\
\text { (DPI) }\end{array}$ & $\begin{array}{l}\text { Outcome } \\
\text { measures }\end{array}$ \\
\hline \multirow[t]{9}{*}{$\begin{array}{l}\text { Rhesus } \\
\text { macaques }\end{array}$} & \multirow[t]{2}{*}{$n=9$} & \multirow[t]{2}{*}{$\begin{array}{l}\text { SARS-CoV-2 } \\
\text { USA-WA1/2020 }\end{array}$} & \multirow{9}{*}{$\begin{array}{l}\text { Reduced } \\
\text { appetite } \\
\text { (35) }\end{array}$} & \multirow{9}{*}{$\begin{array}{l}\text { Nose, pharynx, } \\
\text { trachea, lung, } \\
\text { gastrointestinal tract, } \\
\text { liver, kidney, } \\
\text { pneumocytes I \& II, } \\
\text { ciliated bronchial } \\
\text { epithelial cells (1) }\end{array}$} & $\begin{array}{l}\text { Acute interstitial } \\
\text { pneumonia }\end{array}$ & Neutropenia & \multirow{15}{*}{$\begin{array}{l}\text { IgG anti- SARS- } \\
\text { CoV-2 Spike pro- } \\
\text { tein (35) }\end{array}$} & \multirow{9}{*}{$\begin{array}{l}\text { Immune } \\
\text { protection } \\
\text { after a } \\
\text { second } \\
\text { exposure }\end{array}$} \\
\hline & & & & & Consolidation & $\begin{array}{l}\text { Lymphopenia } \\
\text { (mild and } \\
\text { transitory in } \\
\text { high dose } \\
\text { group) }\end{array}$ & & \\
\hline & \multirow[t]{2}{*}{$6-12$ years } & $\begin{array}{l}\text { initial } \\
\text { inoculation }\end{array}$ & & & Edema & \multirow[t]{7}{*}{$\begin{array}{l}\text { IFN-y } \\
\text { upregulation }\end{array}$} & & \\
\hline & & $1.1 \times 10^{6}, n=3$ & & & $\begin{array}{l}\text { Multiple } \\
\text { Inflammatory foci }\end{array}$ & & & \\
\hline & \multirow[t]{5}{*}{$(M / F)$} & $1.1 \times 10^{5}, n=3$ & & & $\begin{array}{l}\text { Hyaline } \\
\text { membranes }\end{array}$ & & & \\
\hline & & $\begin{array}{l}1.1 \times 10^{4} \mathrm{PFU}, \\
n=3\end{array}$ & & & $\begin{array}{l}\text { Damage to type I } \\
\text { and type II } \\
\text { pneumocytes }\end{array}$ & & & \\
\hline & & $(\mathrm{IN}, \mathrm{IT})$ & & & $\begin{array}{l}\text { Necrotic } \\
\text { bronchiolar } \\
\text { epithelium }\end{array}$ & & & \\
\hline & & & & & $\begin{array}{l}\text { Bronchiolar } \\
\text { epithelial } \\
\text { syncytial cells }\end{array}$ & & & \\
\hline & & & & & $\begin{array}{l}\text { No extra } \\
\text { pulmonary injury }\end{array}$ & & & \\
\hline \multirow{6}{*}{$\begin{array}{l}\text { Chandrashekar } \\
\text { et al. (2020) } \\
\text { [43]c }\end{array}$} & \multirow[t]{3}{*}{$n=9$} & $\begin{array}{l}\text { SARS-CoV-2 } \\
\text { USA-WA1/2020 }\end{array}$ & \multirow[t]{6}{*}{ No (14) } & \multirow{6}{*}{$\begin{array}{l}5 \log _{10} \text { reduction } \\
\text { BAL \& nasal viral } \\
\text { loads (1) }\end{array}$} & \multirow[t]{6}{*}{ NA } & \multirow{6}{*}{$\begin{array}{l}\text { Increased virus- } \\
\text { specific Nab } \\
\text { titers }\end{array}$} & & \\
\hline & & $\begin{array}{l}\text { Second } \\
\text { inoculation }\end{array}$ & & & & & & \\
\hline & & $\begin{array}{l}\text { day } 35 \text { post- } \\
\text { initial infection }\end{array}$ & & & & & & \\
\hline & \multirow[t]{2}{*}{$6-12$ years } & $1.1 \times 10^{6}$ & & & & & & \\
\hline & & $1.1 \times 10^{5}$ & & & & & & \\
\hline & $(M / F)$ & $\begin{array}{l}1.1 \times 10^{4} \mathrm{PFU} \\
(\mathrm{IN}, \mathrm{IT})\end{array}$ & & & & & & \\
\hline \multirow[t]{5}{*}{$\begin{array}{l}\text { Rhesus } \\
\text { macaques }\end{array}$} & \multirow[t]{2}{*}{$n=7$} & SARS-CoV-2 & Fever & \multirow{5}{*}{$\begin{array}{l}\text { Nose, oropharynx, } \\
\text { lung, gut, spinal } \\
\text { cord, bladder, } \\
\text { rectum (3) }\end{array}$} & $\begin{array}{l}\text { Thickened } \\
\text { alveolar septa }\end{array}$ & \multirow[t]{5}{*}{$\begin{array}{l}\text { Increase CD4+ } \\
\text { T cells }\end{array}$} & \multirow{5}{*}{$\begin{array}{l}\text { IgG antibody } \\
\text { anti-SARS-CoV-2 } \\
\text { (14) }\end{array}$} & \multirow{9}{*}{$\begin{array}{l}\text { Immune } \\
\text { protection } \\
\text { after a } \\
\text { second } \\
\text { exposure }\end{array}$} \\
\hline & & $\begin{array}{l}\text { WH-09/hum/ } \\
2020\end{array}$ & Weight loss & & $\begin{array}{l}\text { Macrophages } \\
\text { accumulation in } \\
\text { alveoli } \\
\text { Degeneration } \\
\text { alveolar epithelia }\end{array}$ & & & \\
\hline & \multirow[t]{2}{*}{$3-5$ years } & & $\begin{array}{l}\text { Posture } \\
\text { change }\end{array}$ & & $\begin{array}{l}\text { Inflammatory } \\
\text { infiltrates }(5,7)\end{array}$ & & & \\
\hline & & $\begin{array}{l}\text { Initial } \\
\text { inoculation }\end{array}$ & $\begin{array}{l}\text { Rapid } \\
\text { breathing }\end{array}$ & & & & & \\
\hline & $(\mathrm{NA})$ & $\begin{array}{l}1 \times 10^{6} \mathrm{TCID}_{50} \\
\text { (IT) }\end{array}$ & $\begin{array}{l}\text { Reduced } \\
\text { appetite (28) }\end{array}$ & & & & & \\
\hline \multirow{4}{*}{$\begin{array}{l}\text { Bao et al. } \\
\text { (2020) [44] }\end{array}$} & \multirow[t]{2}{*}{$(n=4)$} & SARS-CoV-2 & \multirow{4}{*}{$\begin{array}{l}\text { Transient } \\
\text { temperature } \\
\text { increase } \\
(14)\end{array}$} & \multirow[t]{4}{*}{ Negative } & No pathology (5) & \multirow{4}{*}{$\begin{array}{l}\text { CD4+ T higher } \\
\text { at } 7 \text { day post- } \\
\text { exposure vs. } \\
\text { post-initial } \\
\text { exposure }\end{array}$} & \multirow{4}{*}{$\begin{array}{l}\text { Higher IgG } \\
\text { antibody anti- } \\
\text { SARS-CoV-2 (14) } \\
\text { Vs. initial } \\
\text { exposure }\end{array}$} & \\
\hline & & $\begin{array}{l}\text { WH-09/hum/ } \\
2020\end{array}$ & & & & & & \\
\hline & $3-5$ years & & & & & & & \\
\hline & $(\mathrm{NA})$ & $\begin{array}{l}\text { second } \\
\text { inoculation day } \\
28 \text { post-initial } \\
\text { infection }\end{array}$ & & & & & & \\
\hline
\end{tabular}


Table 2 Summary of studies using nonhuman primate models of COVID-19 (Continued)

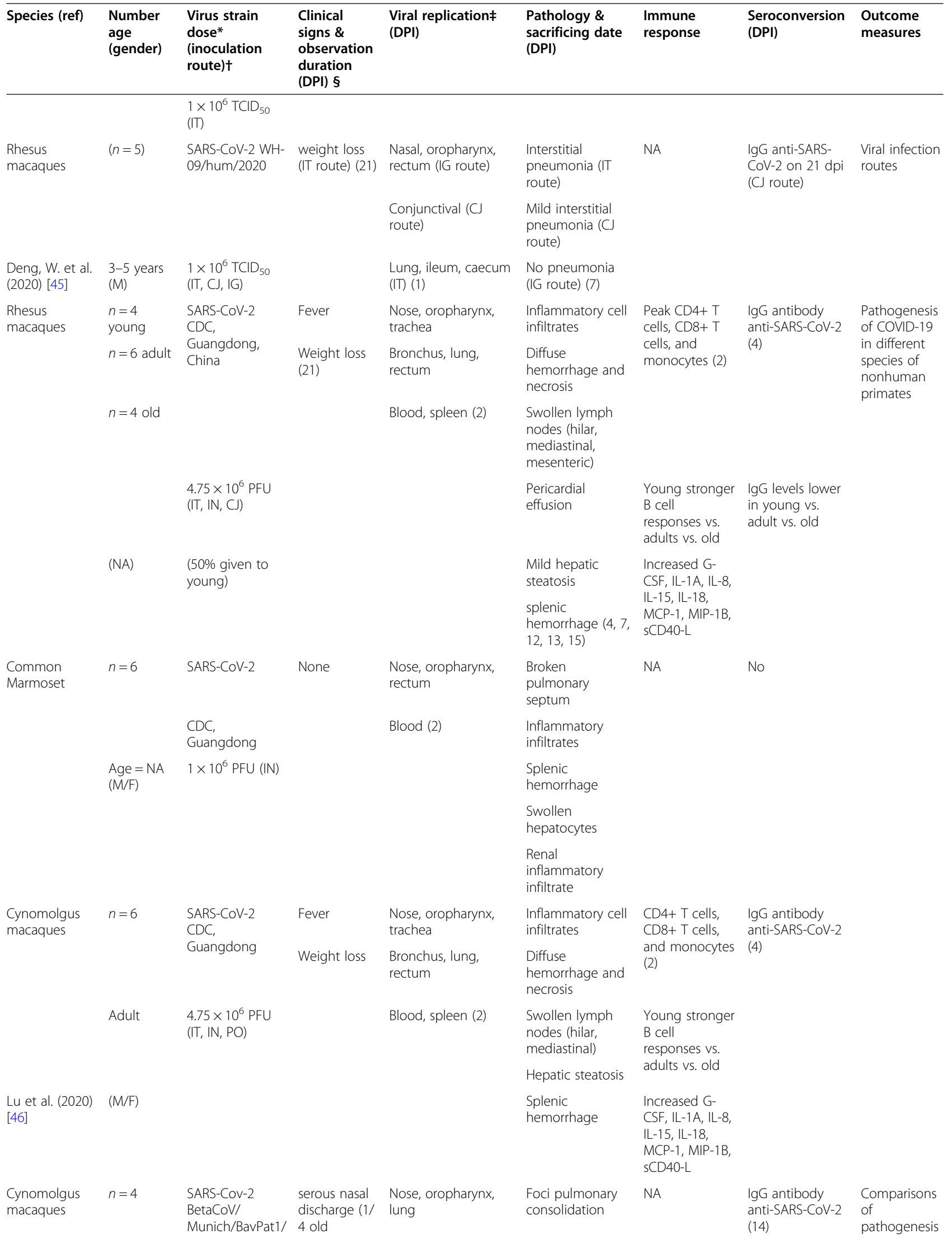


Table 2 Summary of studies using nonhuman primate models of COVID-19 (Continued)

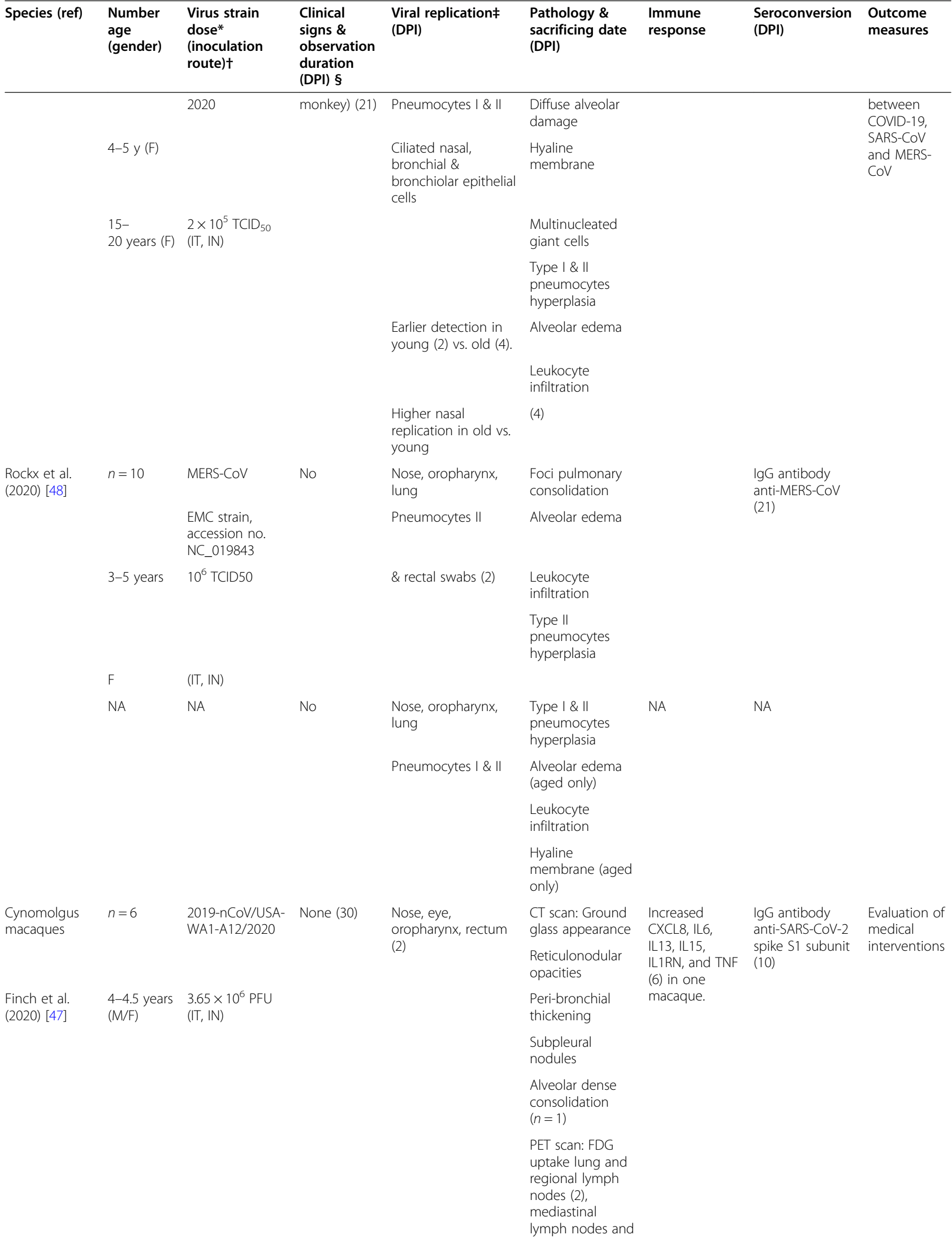


Table 2 Summary of studies using nonhuman primate models of COVID-19 (Continued)

\begin{tabular}{|c|c|c|c|c|c|c|c|c|}
\hline Species (ref) & $\begin{array}{l}\text { Number } \\
\text { age } \\
\text { (gender) }\end{array}$ & $\begin{array}{l}\text { Virus strain } \\
\text { dose* } \\
\text { (inoculation } \\
\text { route) } \dagger\end{array}$ & $\begin{array}{l}\text { Clinical } \\
\text { signs \& } \\
\text { observation } \\
\text { duration } \\
\text { (DPI) § }\end{array}$ & $\begin{array}{l}\text { Viral replication } \neq \\
\text { (DPI) }\end{array}$ & $\begin{array}{l}\text { Pathology \& } \\
\text { sacrificing date } \\
\text { (DPI) }\end{array}$ & $\begin{array}{l}\text { Immune } \\
\text { response }\end{array}$ & $\begin{array}{l}\text { Seroconversion } \\
\text { (DPI) }\end{array}$ & $\begin{array}{l}\text { Outcome } \\
\text { measures }\end{array}$ \\
\hline & & & & & spleen (6) & & & \\
\hline \multirow[t]{2}{*}{$\begin{array}{l}\text { African green } \\
\text { monkey }\end{array}$} & \multirow[t]{2}{*}{$n=6$} & \multirow[t]{2}{*}{$\begin{array}{l}\text { SARS-CoV-2-2/ } \\
\text { INMI1-/2020/Italy }\end{array}$} & $\begin{array}{l}\text { Reduced } \\
\text { appetite }\end{array}$ & \multirow{2}{*}{$\begin{array}{l}\text { Nasal, oropharynx, } \\
\text { lung, rectum, } \\
\text { pneumocytes I \& II, } \\
\text { alveolar } \\
\text { macrophages (2) }\end{array}$} & $\begin{array}{l}\text { Interstitial } \\
\text { pneumonia }\end{array}$ & \multirow[t]{2}{*}{$\begin{array}{l}\text { Increased CRP } \\
\text { I }(n=2)\end{array}$} & \multirow{2}{*}{$\begin{array}{l}\text { IgG antibody } \\
\text { against SARS- } \\
\text { CoV-2 b (5) }\end{array}$} & \multirow[t]{2}{*}{$\begin{array}{l}\text { Pathogenesis } \\
\text { of COVID-19 }\end{array}$} \\
\hline & & & Fever (31) & & Bronchiolitis & & & \\
\hline \multirow{5}{*}{$\begin{array}{l}\text { Woolsey et al. } \\
\text { (2020) [49] }\end{array}$} & \multirow[t]{5}{*}{ NA } & \multirow{5}{*}{$\begin{array}{l}5 \times 10^{5} \mathrm{PFU}(\mathrm{IT} \\
\mathrm{IN})\end{array}$} & & & Edema & \multirow{5}{*}{$\begin{array}{l}\text { IL-8, IP-10, IL- } \\
\text { 12, IL-6, IFN- } \\
\text { beta, IL10, and } \\
\text { MCP-1 (2) }\end{array}$} & & \\
\hline & & & & & Hemorrhage & & & \\
\hline & & & & & $\begin{array}{l}\text { Hyaline } \\
\text { membrane }\end{array}$ & & & \\
\hline & & & & & $\begin{array}{l}\text { Hyperplasia type } \\
\text { II pneumocytes }\end{array}$ & & & \\
\hline & & & & & $\begin{array}{l}\text { Distention and } \\
\text { flaccidity small } \\
\text { intestines } \\
\text { segments } \\
\text { (5) }\end{array}$ & & & \\
\hline
\end{tabular}

${ }^{*} T C I D_{50}$ Median Tissue Culture Infectious Dose at which $50 \%$ of the cells are infected, $P F U$ plaque-forming unit, $+I T$ intratracheal, IN intranasal, $C J$ intraconjunctival, $O C$ ocular, IG intragastric, $P O$ per oral. ₹ Viral replication: RNA copies (PCR), viral antigen (immunostaining), viral particles (electron microscopy). § dpi day post-inoculation, ๆ CRP C-reactive protein, \|NA Not available. **Vaccine encoding spike protein variants: Full-length SARS-CoV-2 $S$ protein, S.dCT Deletion of the cytoplasmic tail of SARS-CoV-2 S protein, S.dTM deletion of the transmembrane domain and cytoplasmic tail reflecting the soluble ectodomain, S1 S1 domain with a fold on trimerization tag, RBD Receptor-binding domain with a fold on trimerization tag, S.dTM.PP a prefusion stabilized soluble ectodomain with deletion of the furin cleavage site, two proline mutations, and a fold on trimerization tag, IM Intramuscular 
other general signs (Table 2). The clinical manifestations were not different between old and young macaques [46-48]. Structural and ultrastructural examination of the respiratory tract were also variables including mild to moderate interstitial pneumonitis, edema, foci of diffuse alveolar damage with occasional hyaline membrane formation, and pneumocytes type II hyperplasia (Table 2). Old rhesus macaques exhibited more diffuse and severe interstitial pneumonia than young ones [47]. The extrapulmonary injury was investigated in five studies $[40,42,43,46,49]$. These revealed pathological changes in two studies $[46,49]$ including distention and flaccidity of the intestine, inflammatory cells infiltrating the jejunum, and colon, steatosis of the liver, and alteration of myocardial fiber architecture with increased mitochondrial density $[46,49]$. No mortality was observed in any of the nonhuman primate models.

Comparisons between species of nonhuman primates were not possible except in one study, which suggested that rhesus macaques were superior to cynomolgus and common marmoset as models of human COVID-19 [46]. Other comparisons suggested that SARS-CoV elicited more severe lung pathology than SARS-CoV-2 and Middle East Respiratory Syndrome (MERS-CoV) [48] (Table 2).

\section{Viral and host interaction}

The virus replicated rapidly and at higher titers in the upper airway and lung in all four species [37-49]. The virus was detected in pneumocytes type I and II and ciliated epithelial cells of nasal, bronchial, and bronchiolar mucosa [37-49]. This differs from MERS-CoV where the virus was mainly present in type II pneumocytes [46] (Table 2). Replication of the virus was also demonstrated in jejunum, duodenum, colon, and rectum [37, 38, 4049]. Viral genome was detected in the blood of rhesus macaques, cynomolgus, and marmoset in one study [46]. Viral replication of nasopharyngeal as well as anal swabs, and the lung in old macaques was higher than in young ones $[47,48]$.

SARS-CoV-2 infection-induced IgG antibodies response against the SARS-CoV-2 spike was noted in all species [37, 46, 48, 49] except in marmoset [46]. The antibodies were protective against a second exposure to the virus $[43,44]$. There was no difference between males and females [37, 39-43, 46, 47]; however, young rhesus macaques had lower antibody titers than the old macaques [46]. The innate immune response to SARS$\mathrm{CoV}-2$ infection was variable with normal, high, or low leucocytes and lymphocyte counts $[37,46]$. Occasional reduction of $\mathrm{CD}^{+}$and $\mathrm{CD} 8^{+} \mathrm{T}$ cell concentrations was documented [37] as well as the transitory release of various cytokines and chemokines at different days postinoculation [37, 46, 49].

\section{Drugs and vaccines}

DNA and inactivated virus-based vaccines were evaluated and showed protection in these nonhuman primates. However, the DNA vaccine did not reduce the virus presence in the upper airway, while there was a residual small interstitial pneumonitis in the macaques that received the inactivated virus $[40,41]$. This suggests that none of the virus tested so far displayed a comprehensive protection against SARS-CoV-2 infection. Several candidate DNA vaccines based in various forms of the SARS-CoV-2 Spike (S) protein were also tested in rhesus macaques [39]. The findings revealed that only the vaccine encoding the full-length $(\mathrm{S})$ offered optimal protection against SARS-CoV-2 [64]. Nonhuman primates served also for the evaluation of antiviral therapies and medical interventions such as CT- and PETscanners [47].

\section{Mouse models \\ Viral model}

Wild type mice (BALB/c, C57BL/6), immunodeficient mice (SCID), chimeric mouse expressing human angiotensinconverting enzyme 2 (hACE2), and the RNA-dependent RNA polymerase (SARS1/SARS2-RdRp) were evaluated as models of COVID-19 (Table 3). Moreover, knockout (KO) mice were generated to test specific immunological pathways or therapy, including ablation of type I (IFNar1-/-), III interferon (IFN) receptors, (IL28r-/-), signal transducer and activator of transcription 2 (STAT2-/-), and serum esterase (Ces1c-/-).

Patient isolates of SARS-CoV-2 from different sources and variable times of passaging on various cell cultures or BALB/c mice were employed (Table 3). Mouseadapted SARS-CoV-2 was developed using two methods. The first by serial passaging (up to 6) through the lungs of $\mathrm{BALB} / \mathrm{c}$ mice until the virus spike receptor-binding domain (RBD) adapted to the murine ACE-2 [54]. In the second, using genetic engineering, the SARS-CoV-2 $\mathrm{RBD}$ was remodeled to enhance its binding efficiency to murine ACE2 [52].

\section{Phenotype}

The clinical signs and symptoms varied from none to mild weight loss, arched back, and slight bristles. Whole-body plethysmography was used to measure the respiratory function of the animals and showed a mild to moderate reduction in old more than in young (Table 3). Likewise, the pathological changes varied according to the experimental models and included peribronchiolar inflammation, lung edema, moderate multifocal interstitial pneumonia, lymphocyte infiltration, and intraalveolar hemorrhage. Survival of hACE2 mice was decreased at 5-day post-inoculation and was attributed to high viral replication in the brain, while it was 
Table 3 Summary of studies using mice models of COVID-19

\begin{tabular}{|c|c|c|c|c|c|c|c|c|}
\hline $\begin{array}{l}\text { Species } \\
\text { (ref) }\end{array}$ & $\begin{array}{l}\text { Number age } \\
\text { (gender) }\end{array}$ & $\begin{array}{l}\text { Virus strain } \\
\text { dose }^{*} \\
\text { (inoculation } \\
\text { route) } \dagger\end{array}$ & $\begin{array}{l}\text { Clinical signs } \\
\& \\
\text { observation } \\
\text { duration } \\
\text { (DPI) } \S \\
\end{array}$ & $\begin{array}{l}\text { Viral } \\
\text { replication } \neq \\
\text { (DPI) }\end{array}$ & $\begin{array}{l}\text { Pathology \& } \\
\text { sacrificing date } \\
\text { (DPI) }\end{array}$ & $\begin{array}{l}\text { Immune } \\
\text { response }\end{array}$ & $\begin{array}{l}\text { Seroconversion } \\
\text { (DPI) }\end{array}$ & $\begin{array}{l}\text { Outcome } \\
\text { Measures }\end{array}$ \\
\hline Mice & $\begin{array}{l}\text { WT-BALB/C, } \\
n=3\end{array}$ & \multirow[t]{4}{*}{$\begin{array}{l}2 \times 10^{5} \text { TCID50 } \\
\text { of P 4t† or } \\
2 \times 10^{6} \text { of } \mathrm{P} \\
6++(\mathrm{N})\end{array}$} & NA & Lung (3) & $\begin{array}{l}\text { Mild lung pathology } \\
\text { (2) }\end{array}$ & \multirow[t]{4}{*}{$\begin{array}{l}\text { Mild } \\
\text { inflammatory } \\
\text { response }\end{array}$} & \multirow[t]{4}{*}{ NA } & \multirow[t]{4}{*}{$\begin{array}{l}\text { Interferon } \\
\text { response to } \\
\text { SARS-CoV-2 } \\
\text { infection }\end{array}$} \\
\hline BALB/C: & $\mathrm{SCID}, n=3$ & & \multirow[t]{3}{*}{ (14) } & \multirow{3}{*}{$\begin{array}{l}\text { No difference } \\
\text { in viral load } \\
\text { WT vs. SCID }\end{array}$} & \multirow{3}{*}{$\begin{array}{l}\text { No difference in } \\
\text { lung pathology WT } \\
\text { vs. SCID } \\
(2,4,7,14)\end{array}$} & & & \\
\hline WTI & & & & & & & & \\
\hline$S C I D \|$ & 6-8 weeks (F) & & & & & & & \\
\hline C57BL/6: & $\begin{array}{l}\mathrm{C} 5 \mathrm{BL} / 6 n= \\
5\end{array}$ & \multirow{4}{*}{$\begin{array}{l}2 \times 10^{5} \text { TCID50 } \\
\text { of P } 4 \text { or } 2 \times \\
10^{6} \text { of P } 6(\mathrm{IN})\end{array}$} & \multirow[t]{4}{*}{$\begin{array}{l}\text { NA } \\
(14)\end{array}$} & \multirow[t]{2}{*}{ Lung (3) } & \multirow{2}{*}{$\begin{array}{l}\text { Greater intra-alveolar } \\
\text { hemorrhage and } \\
\text { peribronchiolar in- } \\
\text { flammation in } \\
\text { IFNar1-/- mice than } \\
\text { WT and IL28r-/- } \\
\text { mice (3) }\end{array}$} & \multirow{4}{*}{$\begin{array}{l}\text { Higher } \\
\text { inflammatory } \\
\text { response in } \\
\text { IFNar1-/- vs. } \\
\text { WT and IL28r } \\
\text {-/- mice }\end{array}$} & \multirow[t]{4}{*}{ NA } & \\
\hline WT & $\begin{array}{l}\text { IFNar1-/_99 } \\
n=14\end{array}$ & & & & & & & \\
\hline Ifnar1-/- & & & & \multirow[b]{2}{*}{$\begin{array}{l}\text { Higher viral } \\
\text { replication in } \\
\text { IFNar1-/- } \\
\text { mice vs. WT } \\
\text { and IL28r-/- } \\
\text { mice }\end{array}$} & \multirow[t]{2}{*}{$(2,4,7,14)$} & & & \\
\hline ||28r-/- & 6-8 weeks (F) & & & & & & & \\
\hline \multirow{3}{*}{$\begin{array}{l}\text { Boudewijns } \\
\text { et al. (2020) } \\
{[56]}\end{array}$} & $\begin{array}{l}\text { C57BL/6, } n= \\
5\end{array}$ & \multirow{3}{*}{$\begin{array}{l}2 \times 10^{5} \text { TCID50 } \\
\text { of P } 4 \text { or } 2 \times \\
10^{6} \text { of P } 6(\mathrm{IN})\end{array}$} & \multirow[t]{3}{*}{$\begin{array}{l}\text { NA } \\
(14)\end{array}$} & Lung (3) & $\begin{array}{l}\text { Mild lung pathology } \\
\text { (3) }\end{array}$ & \multirow{3}{*}{$\begin{array}{l}\text { Mild } \\
\text { inflammatory } \\
\text { response }\end{array}$} & \multirow[t]{3}{*}{ NA } & \\
\hline & $\begin{array}{l}\text { IL28r-I-, } n= \\
5\end{array}$ & & & \multirow{2}{*}{$\begin{array}{l}\text { No difference } \\
\text { in viral load } \\
\text { between WT } \\
\text { and IL28r-/- }\end{array}$} & \multirow[t]{2}{*}{$(2,4,7,14)$} & & & \\
\hline & 6-8 weeks (F) & & & & & & & \\
\hline Mice & hACE2 mice & $\begin{array}{l}\text { SARS-CoV-2 } \\
\text { (BetaCoV/ }\end{array}$ & Slight & $\begin{array}{l}\text { Highest viral } \\
\text { load }\end{array}$ & $\begin{array}{l}\text { Moderate interstitial } \\
\text { pneumonia }\end{array}$ & $\begin{array}{l}\text { MAC2, CD3+ } \\
\text { T and CD19+ }\end{array}$ & $\begin{array}{l}\text { IgG antibody } \\
\text { response }\end{array}$ & $\begin{array}{l}\text { Pathogenesis } \\
\text { of COVID-19 }\end{array}$ \\
\hline \multirow{7}{*}{$\begin{array}{l}\text { hACE2 }\|\| \\
\text { transgenic } \\
\text { mice }\end{array}$} & \multirow[t]{2}{*}{ (ACE2-HB-01) } & $\begin{array}{l}\text { Wuhan/IVDC- } \\
\text { HB-01/ }\end{array}$ & Bristles & In lung (3) & \multirow{2}{*}{$\begin{array}{l}\text { Thickened alveolar } \\
\text { septa }\end{array}$} & $\begin{array}{l}\text { B cells in } \\
\text { alveolar }\end{array}$ & $\begin{array}{l}\text { against SARS- } \\
\text { CoV-2 (21) }\end{array}$ & \\
\hline & & $\begin{array}{l}\text { 2020|EPI_ISL_ } \\
402119)\end{array}$ & Weight loss & Intestine (1) & & septum & & \\
\hline & $n=19$ & \multirow[t]{5}{*}{$10^{5} \mathrm{TCID}_{50}(\mathrm{IN})$} & \multirow{5}{*}{$\begin{array}{l}\text { Arched back } \\
\text { (14) }\end{array}$} & \multirow{5}{*}{$\begin{array}{l}\text { Alveolar } \\
\text { macrophage, } \\
\text { and alveolar } \\
\text { epithelia (3) }\end{array}$} & \multirow{2}{*}{$\begin{array}{l}\text { Lymphocytes, } \\
\text { macrophages, and } \\
\text { monocytes infiltrates } \\
\text { in the interstitial and } \\
\text { alveolar space }\end{array}$} & & & \\
\hline & \multirow[t]{4}{*}{$\begin{array}{l}6-11 \text { months } \\
(\mathrm{M} / \mathrm{F})\end{array}$} & & & & & & & \\
\hline & & & & & $\begin{array}{l}\text { Bronchioles } \\
\text { degeneration (3) }\end{array}$ & & & \\
\hline & & & & & $\begin{array}{l}\text { No pathology in } \\
\text { intestine, spleen, } \\
\text { heart, liver, kidney, } \\
\text { brain, and testis }\end{array}$ & & & \\
\hline & & & & & $(1,3,5,7)$ & & & \\
\hline \multirow[t]{4}{*}{$\begin{array}{l}\text { Bao et al. } \\
\text { (2020) [50] }\end{array}$} & $\begin{array}{l}\text { WT-HB-01 } \\
(n=15)\end{array}$ & \multirow{2}{*}{$\begin{array}{l}\text { SARS-CoV-2 } \\
\text { (BetaCoV/ } \\
\text { Wuhan/IVDC- } \\
\text { HB-01/ } \\
2020 \mid \text { EPI_ISL_ } \\
402119 \text { ) } \\
10^{5} \text { TCID }_{50}(\text { IN) }\end{array}$} & \multirow[t]{2}{*}{$\begin{array}{l}\text { No } \\
(14)\end{array}$} & $\begin{array}{l}\text { No viral RNA } \\
\text { detectable in }\end{array}$ & $\begin{array}{l}\text { No } \\
(1,3,5,7)\end{array}$ & No & No & \\
\hline & $\begin{array}{l}6-11 \text { months } \\
(\mathrm{M} / \mathrm{F})\end{array}$ & & & $\begin{array}{l}\text { lung or } \\
\text { intestine (1) }\end{array}$ & & & & \\
\hline & $\begin{array}{l}\text { Mock-treated } \\
\text { hACE2 mice } \\
(n=15)\end{array}$ & $\begin{array}{l}\text { PBS } 50 \mu \mathrm{l} \\
(\mathrm{IN})\end{array}$ & $\begin{array}{l}\text { No } \\
(14)\end{array}$ & $\begin{array}{l}\text { No viral RNA } \\
\text { detectable in } \\
\text { lung or }\end{array}$ & $\begin{array}{l}\text { No } \\
(1,3,5,7)\end{array}$ & No & No & \\
\hline & $\begin{array}{l}6-11 \text { months } \\
(\mathrm{M} / \mathrm{F})\end{array}$ & & & intestine & & & & \\
\hline
\end{tabular}


Table 3 Summary of studies using mice models of COVID-19 (Continued)

\begin{tabular}{|c|c|c|c|c|c|c|c|c|}
\hline $\begin{array}{l}\text { Species } \\
\text { (ref) }\end{array}$ & $\begin{array}{l}\text { Number age } \\
\text { (gender) }\end{array}$ & $\begin{array}{l}\text { Virus strain } \\
\text { dose* }^{*} \\
\text { (inoculation } \\
\text { route)† }\end{array}$ & $\begin{array}{l}\text { Clinical signs } \\
\& \\
\text { observation } \\
\text { duration } \\
\text { (DPI) § }\end{array}$ & $\begin{array}{l}\text { Viral } \\
\text { replication } \neq \\
\text { (DPI) }\end{array}$ & $\begin{array}{l}\text { Pathology \& } \\
\text { sacrificing date } \\
\text { (DPI) }\end{array}$ & $\begin{array}{l}\text { Immune } \\
\text { response }\end{array}$ & $\begin{array}{l}\text { Seroconversion } \\
\text { (DPI) }\end{array}$ & $\begin{array}{l}\text { Outcome } \\
\text { Measures }\end{array}$ \\
\hline \multirow[t]{3}{*}{ Mice } & $\begin{array}{l}n=5 \\
6-8 \text { weeks } \\
\text { (M) }\end{array}$ & $\begin{array}{l}\text { SARS-CoV-2 } \\
\text { (BetaCoV/ } \\
\text { Hong Kong/ } \\
\text { VM20001061/ } \\
2020[\mathrm{KH} 1] \text { ) }\end{array}$ & \multirow[t]{3}{*}{ NA } & \multirow[t]{3}{*}{ NA } & \multirow[t]{3}{*}{ NA } & \multirow[t]{3}{*}{ NA } & \multirow[t]{3}{*}{$\begin{array}{l}\text { IgG antibody } \\
\text { response } \\
\text { against SARS- } \\
\text { CoV and SARS- } \\
\text { CoV-2 spike pro- } \\
\text { tein and RBD }\end{array}$} & \multirow[t]{6}{*}{$\begin{array}{l}\text { Cross- } \\
\text { reactivity of } \\
\text { antibodies } \\
\text { against SARS- } \\
\text { CoV and } \\
\text { SARS-CoV-2 }\end{array}$} \\
\hline & \multirow[t]{2}{*}{ Infection } & $\begin{array}{l}\text { SARS-CoV } \\
\text { (HK39849, } \\
\text { SCoV) }\end{array}$ & & & & & & \\
\hline & & $10^{5} \mathrm{PFU}(\mathrm{IN})$ & & & & & & \\
\hline BALB/C: & $n=5$ & \multirow{3}{*}{$\begin{array}{l}\text { Immunization } \\
\text { with heat- } \\
\text { inactivated } \\
\text { plasma from } \\
\text { SARS-CoV and } \\
\text { SARS-CoV-2 } \\
\text { (IP) }\end{array}$} & \multirow[t]{3}{*}{ NA } & \multirow[t]{3}{*}{ NA } & \multirow[t]{3}{*}{ NA } & \multirow[t]{3}{*}{ NA } & \multirow{5}{*}{$\begin{array}{l}\text { Cross-reactive } \\
\text { antibody } \\
\text { binding } \\
\text { responses SARS- } \\
\text { CoV-2 and } \\
\text { SARS-CoV } \\
\text { No cross- } \\
\text { neutralization } \\
\text { SARS-CoV-2 and } \\
\text { SARS-CoV }\end{array}$} & \\
\hline $\begin{array}{l}\text { WT } \\
\text { Lv et al. } \\
\text { (2020) [53] }\end{array}$ & $\begin{array}{l}6-8 \text { weeks } \\
\text { (M) }\end{array}$ & & & & & & & \\
\hline \multirow[t]{3}{*}{$\begin{array}{l}\text { Lv et al. } \\
(2020)[53]\end{array}$} & Immunization & & & & & & & \\
\hline & $n=6$ & \multirow[t]{2}{*}{ Vehicle (IN) } & \multirow[t]{2}{*}{ NA } & \multirow[t]{2}{*}{ NA } & \multirow[t]{2}{*}{ NA } & \multirow[t]{2}{*}{ NA } & & \\
\hline & $\begin{array}{l}6-8 \text { weeks } \\
\text { (M) } \\
\text { control }\end{array}$ & & & & & & & \\
\hline $\begin{array}{l}\text { Transgenic } \\
\text { mice }\end{array}$ & $n=7$ & $\begin{array}{l}\text { SARS1/SARS2- } \\
\operatorname{RdRp} \S \S\end{array}$ & $\begin{array}{l}\text { Improvement } \\
\text { of pulmonary } \\
\text { function }\end{array}$ & $\begin{array}{l}\text { reduced lung } \\
\text { viral load } 10^{2} \\
\text { PFU/lobe (5) }\end{array}$ & $\begin{array}{l}\text { Decreased lung } \\
\text { hemorrhage (5) } \\
\text { (5) }\end{array}$ & NA & NA & $\begin{array}{l}\text { Antiviral } \\
\text { therapy } \\
\text { testing }\end{array}$ \\
\hline C57BL/ $6^{* * *}:$ & 17 weeks (F) & $10^{3} \mathrm{PFU}(\mathrm{IN})$ & \multirow[t]{3}{*}{ (5) } & & & & & \\
\hline Ces1c-/- & & Remdesivir & & & & & & \\
\hline \multirow{9}{*}{$\begin{array}{l}\text { Pruijssers } \\
\text { et al. (2020) } \\
\text { [55] }\end{array}$} & Remdesivir & & & & & & & \\
\hline & $n=7$ & $\begin{array}{l}\text { SARS1/SARS2- } \\
\text { RdRp }\end{array}$ & \multirow{3}{*}{$\begin{array}{l}\text { Reduced } \\
\text { pulmonary } \\
\text { function by } \\
\text { WPH+†† } \\
\text { (5) }\end{array}$} & $\begin{array}{l}\text { Lung viral } \\
\text { load }\end{array}$ & \multirow{3}{*}{$\begin{array}{l}\text { Lung hemorrhage } \\
\text { (5) } \\
(5)\end{array}$} & \multirow[t]{3}{*}{ NA } & \multirow[t]{3}{*}{ NA } & \\
\hline & 17 weeks $(F)$ & $10^{3} \mathrm{PFU}(\mathrm{IN})$ & & \multirow{2}{*}{$\begin{array}{l}10^{5} \text { PFU/lobe } \\
(5)\end{array}$} & & & & \\
\hline & Control & Vehicle & & & & & & \\
\hline & $n=3$ & \multirow{3}{*}{$\begin{array}{l}\text { Mouse- } \\
\text { adapted SARS- } \\
\text { CoV-2 (Beta- } \\
\text { CoV/Wuhan/ } \\
\text { AMMS01/ } \\
\text { 2020) }\end{array}$} & \multirow{5}{*}{$\begin{array}{l}\text { Weight loss } \\
\text { old mice (5) } \\
\text { (7) }\end{array}$} & \multirow{3}{*}{$\begin{array}{l}\text { Trachea, lung, } \\
\text { heart, liver, } \\
\text { and intestine, } \\
\text { pneumocytes } \\
\text { Type II }\end{array}$} & $\begin{array}{l}\text { Thickened alveolar } \\
\text { septa }\end{array}$ & $\begin{array}{l}\text { Increased } \\
\text { TNF-a, IL-1 } \beta \text {, }\end{array}$ & NA & $\begin{array}{l}\text { Establishment } \\
\text { of mouse- }\end{array}$ \\
\hline & $\begin{array}{l}\text { Young, } 6 \\
\text { weeks (F) }\end{array}$ & & & & $\begin{array}{l}\text { Alveolar damage } \\
\text { and focal exudation }\end{array}$ & $\begin{array}{l}\text { MCP-1, G- } \\
\text { CSF, and GM- }\end{array}$ & & $\begin{array}{l}\text { CoV-2 model } \\
\text { of COVID19 }\end{array}$ \\
\hline & & & & & Hemorrhage, & & & \\
\hline & $n=3$ & $\begin{array}{l}7.2 \times 10^{5} \mathrm{PFU} \\
(\mathrm{IN})\end{array}$ & & $\begin{array}{l}\text { Viral } \\
\text { replication }\end{array}$ & $\begin{array}{l}\text { Inflammatory cell } \\
\text { infiltration }\end{array}$ & $\begin{array}{l}\text { Higher and } \\
\text { sustained }\end{array}$ & & \\
\hline & & & & $\begin{array}{l}\text { similar in old } \\
\text { vs. young } \\
\text { cells (3) }\end{array}$ & $\begin{array}{l}\text { Denaturation of } \\
\text { endothelial tissues } \\
\text { (3) }\end{array}$ & $\begin{array}{l}\text { cytokines } \\
\text { levels in aged } \\
\text { mice vs. } \\
\text { young }\end{array}$ & & \\
\hline Mice & Old, 9 & & & & Lung pathology & & & \\
\hline BALB/C: & & & & & $\begin{array}{l}\text { similar in old vs. } \\
\text { young mice } \\
(3,5,7)\end{array}$ & & & \\
\hline WT & Control mice & NA & No weight & No viral & NO & NO & & Evaluation of \\
\hline Gu et al. & NA & & & & & & & $\begin{array}{l}\text { candidates } \\
\text { vaccine }\end{array}$ \\
\hline & $n=10$ & $\begin{array}{l}\text { Immunization } \\
\text { day } 1,14\end{array}$ & NA & $\begin{array}{l}\text { No viral } \\
\text { replication }\end{array}$ & No & NA & $\begin{array}{l}\text { Higher lgG } \\
\text { antibody }\end{array}$ & \\
\hline & $6-8$ weeks & Challenged & & $\begin{array}{l}\text { detectable in } \\
\text { lungs (5) }\end{array}$ & & & $\begin{array}{l}\text { response } \\
\text { against SARS- }\end{array}$ & \\
\hline
\end{tabular}


Table 3 Summary of studies using mice models of COVID-19 (Continued)

\begin{tabular}{|c|c|c|c|c|c|c|c|c|}
\hline $\begin{array}{l}\text { Species } \\
\text { (ref) }\end{array}$ & $\begin{array}{l}\text { Number age } \\
\text { (gender) }\end{array}$ & $\begin{array}{l}\text { Virus strain } \\
\text { dose* } \\
\text { (inoculation } \\
\text { route) } \dagger\end{array}$ & $\begin{array}{l}\text { Clinical signs } \\
\& \\
\text { observation } \\
\text { duration } \\
\text { (DPI) § }\end{array}$ & $\begin{array}{l}\text { Viral } \\
\text { replication } \neq \\
(D P I)\end{array}$ & $\begin{array}{l}\text { Pathology \& } \\
\text { sacrificing date } \\
\text { (DPI) }\end{array}$ & $\begin{array}{l}\text { Immune } \\
\text { response }\end{array}$ & $\begin{array}{l}\text { Seroconversion } \\
\text { (DPI) }\end{array}$ & $\begin{array}{l}\text { Outcome } \\
\text { Measures }\end{array}$ \\
\hline & & $\begin{array}{l}\text { with mouse } \\
\text { adapted SARS- } \\
\text { CoV-2 }\end{array}$ & & & & & CoV-2 (14) & \\
\hline & $\begin{array}{l}\text { Immunized } \\
\text { with SARS- } \\
\text { CoV-2 RBD-FC } \\
\text { protein }\end{array}$ & $\begin{array}{l}\text { (IN), } 4 \text { weeks } \\
\text { after second } \\
\text { immunization }\end{array}$ & & & & & & \\
\hline & $\begin{array}{l}\text { PBS control } \\
\text { with } \\
\text { aluminum } \\
\text { adjuvant }\end{array}$ & & & $\begin{array}{l}\text { High viral } \\
\text { load in the } \\
\text { trachea and } \\
\text { lungs (5) }\end{array}$ & $\begin{array}{l}\text { Focal perivascular } \\
\text { and peribronchiolar } \\
\text { inflammation } \\
\text { Thickened alveolar } \\
\text { septa }\end{array}$ & NA & NA & \\
\hline \multirow[t]{4}{*}{ Mice } & $n=5$ & SARS-CoV-2 & \multirow{5}{*}{$\begin{array}{l}\text { No } \\
(2)\end{array}$} & \multirow{5}{*}{$\begin{array}{l}\text { No viral } \\
\text { replication } \\
\text { detectable in } \\
\text { lung (2) }\end{array}$} & \multirow[t]{5}{*}{ NA } & \multirow[t]{5}{*}{ NA } & \multirow{5}{*}{$\begin{array}{l}\text { IgG1 ab1 } \\
\text { protects hACE2 } \\
\text { transgenic mice } \\
\text { from SARS-CoV- } \\
2 \text { infection. } \\
\text { (2) }\end{array}$} & \multirow{5}{*}{$\begin{array}{l}\text { Evaluation of } \\
\text { prophylaxis } \\
\text { with } \\
\text { monoclonal } \\
\text { antibody }\end{array}$} \\
\hline & 6-9 weeks (F) & $10^{5} \mathrm{PFU}(\mathrm{IN})$ & & & & & & \\
\hline & $\begin{array}{l}\text { C3B6: hACE2 } \\
\text { mice }\end{array}$ & & & & & & & \\
\hline & Immunization & $\begin{array}{l}\text { Human } \\
\text { monoclonal } \\
\text { lgG1 antibody } \\
(12 \mathrm{~h})\end{array}$ & & & & & & \\
\hline C3B6: & & $\begin{array}{l}\text { Prior the virus } \\
\text { challenges (IP) }\end{array}$ & & & & & & \\
\hline \multirow{3}{*}{$\begin{array}{l}\text { hACE2 } \\
\text { transgenic } \\
\text { mice }\end{array}$} & $n=6$ & SARS-CoV-2 & \multirow{4}{*}{$\begin{array}{l}\text { No } \\
\text { (2) }\end{array}$} & \multirow{4}{*}{$\begin{array}{l}\text { Viral } \\
\text { replication } \\
10^{3} \mathrm{PFU} \text { per } \\
\text { lung (2) }\end{array}$} & \multirow[t]{4}{*}{ NA } & \multirow[t]{4}{*}{ NA } & \multirow[t]{4}{*}{ No } & \\
\hline & 6-9 weeks (F) & $10^{5} \mathrm{PFU}(\mathrm{IN})$ & & & & & & \\
\hline & $\begin{array}{l}\text { C3B6: hACE2 } \\
\text { mice }\end{array}$ & & & & & & & \\
\hline $\begin{array}{l}\mathrm{BALB} / \mathrm{C} \\
\text { mice }\end{array}$ & Control & $\begin{array}{l}\text { IgG1 m336 (no } \\
\text { activity } \\
\text { in vitro) }\end{array}$ & & & & & & \\
\hline \multirow{5}{*}{$\begin{array}{l}\text { Li et al. } \\
\text { (2020) [51] }\end{array}$} & Balb/c, $n=5$ & \multirow{2}{*}{ 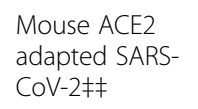 } & \multirow{5}{*}{$\begin{array}{l}\text { No } \\
(2)\end{array}$} & \multirow{5}{*}{$\begin{array}{l}\text { No viral } \\
\text { replication } \\
\text { detectable in } \\
\text { lung lobe at } \\
\text { different } \\
\text { dosages (2) }\end{array}$} & \multirow[t]{5}{*}{ NA } & \multirow[t]{5}{*}{ NA } & \multirow{5}{*}{$\begin{array}{l}\text { IgG1 ab1 } \\
\text { protected mice } \\
\text { SARS-CoV-2 } \\
\text { challenge } \\
\text { (2) }\end{array}$} & \\
\hline & \multirow{4}{*}{$\begin{array}{l}\text { 10-12 } \\
\text { months (F) }\end{array}$} & & & & & & & \\
\hline & & $10^{5} \mathrm{PFU}(\mathrm{IN})$ & & & & & & \\
\hline & & $\begin{array}{l}\text { Human } \\
\text { monoclonal } \\
\text { lgG1 ab1 } \\
\text { antibody (12 } \\
\text { h) }\end{array}$ & & & & & & \\
\hline & & $\begin{array}{l}\text { Prior the virus } \\
\text { challenges (IP) }\end{array}$ & & & & & & \\
\hline Mice & hACE2 mice & SARS-CoV-2 & Weight loss & Lung (2), & NA & NA & NA & Evaluation of \\
\hline $\begin{array}{l}\text { BALB/C: } \\
\text { And } \\
\text { hACE2 }\end{array}$ & NA & $10^{5} \mathrm{PFU}(\mathrm{IN})$ & $\begin{array}{l}\text { Mortality } 40 \% \\
\text { (5) } \\
\text { (5) }\end{array}$ & & & & & $\begin{array}{l}\text { vaccine and } \\
\text { therapy in } \\
\text { mouse- } \\
\text { adapted }\end{array}$ \\
\hline $\begin{array}{l}\text { Transgenic } \\
\text { mice }\end{array}$ & BALB/c mice & $\begin{array}{l}\text { SARS-CoV- } \\
2 \mathrm{MA}^{\S}\end{array}$ & $\begin{array}{l}\text { Pulmonary } \\
\text { obstruction } \\
(\text { WBP })^{++}\end{array}$ & Upper airway & & NA & NA & $\begin{array}{l}\text { SARS-CoV-2 } \\
\text { model }\end{array}$ \\
\hline \multirow{4}{*}{$\begin{array}{l}\text { Dinnon } \\
\text { et al. (2020) } \\
\text { [52] }\end{array}$} & $n=33$ & $10^{5} \mathrm{PFU}(\mathrm{IN})$ & & Lung $(2,4)$ & \multirow{4}{*}{$\begin{array}{l}\text { Greater lung } \\
\text { inflammation and } \\
\text { hemorrhage in old } \\
\text { vs. young mice }(2,4)\end{array}$} & & & \\
\hline & $\begin{array}{l}\text { Young } 12 \\
\text { weeks }\end{array}$ & & & & & & & \\
\hline & BALB/c mice & & Greater & \multirow{2}{*}{$\begin{array}{l}\text { Higher } \\
\text { replication in } \\
\text { old vs. young }\end{array}$} & & & & \\
\hline & $n=34$ & & Weight and & & & & & \\
\hline
\end{tabular}


Table 3 Summary of studies using mice models of COVID-19 (Continued)

\begin{tabular}{|c|c|c|c|c|c|c|c|c|}
\hline $\begin{array}{l}\text { Species } \\
\text { (ref) }\end{array}$ & $\begin{array}{l}\text { Number age } \\
\text { (gender) }\end{array}$ & $\begin{array}{l}\text { Virus strain } \\
\text { dose* } \\
\text { (inoculation } \\
\text { route)† }\end{array}$ & $\begin{array}{l}\text { Clinical signs } \\
\& \\
\text { observation } \\
\text { duration } \\
\text { (DPI) § }\end{array}$ & $\begin{array}{l}\text { Viral } \\
\text { replication‡ } \\
\text { (DPI) }\end{array}$ & $\begin{array}{l}\text { Pathology \& } \\
\text { sacrificing date } \\
\text { (DPI) }\end{array}$ & $\begin{array}{l}\text { Immune } \\
\text { response }\end{array}$ & $\begin{array}{l}\text { Seroconversion } \\
\text { (DPI) }\end{array}$ & $\begin{array}{l}\text { Outcome } \\
\text { Measures }\end{array}$ \\
\hline & & & pulmonary & \multirow[t]{2}{*}{ mice } & & & & \\
\hline & 12 months & & $\begin{array}{l}\text { Function loss } \\
\text { in old vs. } \\
\text { young mice }\end{array}$ & & & & & \\
\hline & Vaccination & SARS-CoV-2 & NA & \multirow{4}{*}{$\begin{array}{l}\text { Vaccine with } \\
\text { spike S } \\
\text { reduced lung } \\
\text { and nasal } \\
\text { turbinate titer } \\
\text { (2) }\end{array}$} & \multirow[t]{4}{*}{ NA } & \multirow[t]{4}{*}{ NA } & \multirow[t]{4}{*}{ NA } & \\
\hline & $n=8-10$ & $\begin{array}{l}\text { spike (S) or } \\
\text { nucleocapsid } \\
(\mathrm{N})\end{array}$ & & & & & & \\
\hline & 10 weeks & $\begin{array}{l}\text { Challenged } 4 \\
\text { weeks post- } \\
\text { inoculation } \\
\text { with SARS- } \\
\text { CoV-2 MA }\end{array}$ & & & & & & \\
\hline & $\mathrm{BALB} / \mathrm{C}$ & $10^{5} \mathrm{PFU}(\mathrm{IN})$ & & & & & & \\
\hline & Prophylaxis & $\begin{array}{l}\text { Subcutaneous } \\
\text { administration } \\
\text { interferon (IFN) } \\
\text { lambda-1a } \\
2 \mu \mathrm{g}\end{array}$ & & \multirow[t]{5}{*}{$\begin{array}{l}\text { Reduced } \\
\text { SARS-CoV-2 } \\
\text { MA replica- } \\
\text { tion in the } \\
\text { lung (2) }\end{array}$} & \multirow[t]{5}{*}{ NA } & \multirow[t]{5}{*}{ NA } & \multirow[t]{5}{*}{ NA } & \\
\hline & Therapy & $\begin{array}{l}18 \mathrm{~h} \text { prior or } \\
12 \mathrm{~h} \text { after }\end{array}$ & & & & & & \\
\hline & $\mathrm{BALB} / \mathrm{C}$ & $\begin{array}{l}\text { SARS-CoV-2 } \\
\text { MA }\end{array}$ & & & & & & \\
\hline & 12 weeks & $10^{5} \mathrm{PFU}(\mathrm{IN})$ & & & & & & \\
\hline & $n=N A$ & & & & & & & \\
\hline
\end{tabular}

${ }^{*} T C I D_{50}$ Median Tissue Culture Infectious Dose at which $50 \%$ of the cells are infected, PFU plaque-forming unit, $+I N$ intranasal, IP intraperitoneal. ₹ Viral replication: RNA copies (PCR), viral antigen (immunostaining), viral particles (electron microscopy). § dpi day post-inoculation. ๆ WT wild type, \| SCID severe combined immunodeficiency (lacking functional T and B cells). ** SARS-CoV-2MA A recombinant mouse ACE2 adapted SARS-CoV-2 variant remodeled by introduction of two amino acid changes at the ACE2 binding pocket in the receptor-binding domain to facilitate efficient binding to mouse ACE2. †† P4 and P6: Number of serial

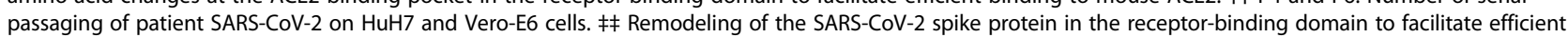
binding to mouse ACE2. §§ Chimeric mouse-adapted SARS-CoV1 MA15 variant encoding the SARS-CoV2 RNA-dependent RNA polymerase ("SARS1/SARS2-RdRp"). 9ा Genetic ablation of type I (Ifnar1-/-), III interferon (IFN) receptors (III28r-/-), and Signal transducer and activator of transcription 2 (STAT2-/-). IIII hACE2 chimera expressing human ACE2 receptor. ${ }^{* * *}$ C57BL/6 Mice Ces1c-/-: lack a serum esterase, an enzyme that is not present in humans, that reduces markedly the Remdesivir half-life. $++\dagger W P H$ whole-body plethysmography

minimal in the lung, suggesting a different pathogenic mechanism of death from human COVID-19 [52]. Wild type mice showed no pathology as compared to hACE2 mice, indicating that the lack of human ACE2 receptor cannot be infected or inefficiently with SARS-CoV-2 [50, 56]. On the other hand, mouse-adapted SARS-CoV-2 exhibited more severe pathology, particularly in the aged mouse than hACE2 transgenic mouse, suggesting that these models may be more relevant for the study of human COVID-19 [52, 54]. However, whether the pathogenesis induced by the mouse-adapted SARS-CoV-2 is translatable to humans warrants further studies $[52,54]$.

\section{Viral and host interaction}

The virus replicated to high titers in the upper and lower respiratory tract in most of the genetically modified mice models but not in wild type. Viral replication was detected outside the respiratory tract in the intestine of
hACE2 mice [50] as well as in the liver, and heart in mouse modified SARS-CoV-2 RBD [52]. Increased viral replication in KO mice IFNar1-/- suggested that interferon limited the viral replication [56].

Specific IgG antibodies against SARS-CoV-2 were documented in two studies (Table 3). The IgG antibodies were found to cross-react in their binding to the spike protein of SARS-CoV, however, with no crossneutralization, hence suggesting the conservation of the same spike protein epitopes among coronaviruses [53]. Proinflammatory cytokines and chemokines were demonstrated in mouse-adapted SARS-CoV-2 and $\mathrm{KO}$ mouse (Table 3 ). The inflammatory response was significantly higher in the old than young mice.

\section{Drugs and vaccines}

Antiviral therapies, including remdesivir [55], IFN lambda [52], and human monoclonal IgG1 antibody 
Table 4 Summary of studies using hamsters models of COVID-19

\begin{tabular}{|c|c|c|c|c|c|c|c|c|}
\hline $\begin{array}{l}\text { Species } \\
\text { (ref) }\end{array}$ & $\begin{array}{l}\text { Number } \\
\text { age } \\
\text { (gender) }\end{array}$ & $\begin{array}{l}\text { Virus strain } \\
\text { dose* } \\
\text { (inoculation } \\
\text { route) } \dagger\end{array}$ & $\begin{array}{l}\text { Clinical } \\
\text { signs \& } \\
\text { observation } \\
\text { duration } \\
\text { (DPI) § }\end{array}$ & $\begin{array}{l}\text { Viral } \\
\text { replication } \neq \\
\text { (DPI) }\end{array}$ & $\begin{array}{l}\text { Pathology \& } \\
\text { sacrificing date } \\
\text { (DPI) }\end{array}$ & Immune response & $\begin{array}{l}\text { Seroconversion } \\
\text { (DPI) }\end{array}$ & $\begin{array}{l}\text { Outcome } \\
\text { measures }\end{array}$ \\
\hline \multirow{9}{*}{$\begin{array}{l}\text { Syrian } \\
\text { hamsters } \\
\text { Chan et al. } \\
\text { (2020) [57] }\end{array}$} & \multirow[t]{2}{*}{$n=8$} & \multirow[t]{2}{*}{$\begin{array}{l}\text { SARS-CoV-2 } \\
\text { Hong Kong }\end{array}$} & Tachypnea & $\begin{array}{l}\text { Nose, trachea, } \\
\text { lung }\end{array}$ & \multirow[t]{2}{*}{$\begin{array}{l}\text { Diffuse alveolar } \\
\text { damage (exudative) }\end{array}$} & \multirow{2}{*}{$\begin{array}{l}\text { Upregulation of } \\
\text { Interferon- } y \text { and } \\
\text { proinflammatory } \\
\text { chemokine, cytokine } \\
\text { genes expression }\end{array}$} & \multirow{2}{*}{$\begin{array}{l}\text { IgG antibody } \\
\text { response } \\
\text { against SARS- } \\
\text { CoV-2 } \\
\text { (7) }\end{array}$} & \multirow{9}{*}{$\begin{array}{l}\text { Viral } \\
\text { transmission } \\
\text { and } \\
\text { immunoprophylaxis }\end{array}$} \\
\hline & & & Weight loss & $\begin{array}{l}\text { Intestine (high } \\
\text { viral load } 9)(2-7)\end{array}$ & & & & \\
\hline & \multirow{5}{*}{$\begin{array}{l}6-10 \\
\text { weeks } \\
\text { (M/F) } \\
\text { (Donor) }\end{array}$} & \multirow[t]{5}{*}{$10^{5} \mathrm{PFU}(\mathrm{IN})$} & Lethargy & & Apoptosis & & & \\
\hline & & & Ruffled furs & \multirow[t]{4}{*}{$\begin{array}{l}\text { Blood (low viral } \\
\text { load) }\end{array}$} & $\begin{array}{l}\text { Diffuse alveolar } \\
\text { damage } \\
\text { (proliferative) }\end{array}$ & \multirow{4}{*}{$\begin{array}{l}\text { Early convalescent } \\
\text { serum } \\
\text { Immunoprophylaxis } \\
\text { decreased nasal and } \\
\text { lung viral load but } \\
\text { not lung pathology } \\
\text { or clinical signs }\end{array}$} & & \\
\hline & & & \multirow{3}{*}{$\begin{array}{l}\text { Hunched } \\
\text { back posture } \\
\text { (14) }\end{array}$} & & Tissue repair & & & \\
\hline & & & & & $\begin{array}{l}\text { Intestinal villi } \\
\text { damage and } \\
\text { necrosis }\end{array}$ & & & \\
\hline & & & & & $\begin{array}{l}\text { Reduced spleen size } \\
(2-14) \\
(2,4,7,14)\end{array}$ & & & \\
\hline & $n=8$ & $\begin{array}{l}\text { Direct } \\
\text { contact with } \\
\text { donor }\end{array}$ & \multirow{2}{*}{$\begin{array}{l}\text { Less weight } \\
\text { loss than } \\
\text { inoculated } \\
\text { animals } \\
\text { (14) }\end{array}$} & \multirow{2}{*}{$\begin{array}{l}\text { No difference in } \\
\text { viral load } \\
\text { inoculated } \\
\text { animals vs. } \\
\text { infected animals } \\
\text { via contact (4) }\end{array}$} & \multirow{2}{*}{$\begin{array}{l}\text { No difference } \\
\text { inoculated vs. } \\
\text { infected by contact } \\
(2,4,7,14)\end{array}$} & \multirow[t]{2}{*}{ NA } & \multirow{2}{*}{$\begin{array}{l}\text { IgG antibody } \\
\text { response } \\
\text { against SARS- } \\
\text { CoV-2 } \\
\text { (7) }\end{array}$} & \\
\hline & $\begin{array}{l}6-10 \\
\text { weeks } \\
\text { (M/F) }\end{array}$ & $\begin{array}{l}\text { Inoculated } \\
\text { with } 100 \mathrm{ul} \\
\text { of PBS }\end{array}$ & & & & & & \\
\hline \multirow[t]{3}{*}{$\begin{array}{l}\text { Syrian } \\
\text { hamsters }\end{array}$} & \multirow{3}{*}{$\begin{array}{l}n=6 \\
\text { (mAb } \\
\text { CC12.1 } \\
\text { or } \\
\text { CC12.23) } \\
\text { ๆ }\end{array}$} & $\begin{array}{l}\text { SARS-CoV-2 } \\
\text { (USAWA1/ } \\
\text { 2020) }\end{array}$ & \multirow{3}{*}{$\begin{array}{l}\text { Weight loss } \\
\text { dose- } \\
\text { dependent } \\
\text { (5) }\end{array}$} & \multirow[t]{3}{*}{$\begin{array}{l}\text { Reduced lung } \\
\text { viral load }\end{array}$} & \multirow[t]{3}{*}{$\begin{array}{l}\text { NA } \\
(5)\end{array}$} & \multirow[t]{3}{*}{ NA } & \multirow[t]{3}{*}{$\begin{array}{l}\text { Neutralizing } \\
\text { antibody } \\
\text { (5) }\end{array}$} & \multirow[t]{6}{*}{$\begin{array}{l}\text { Immunoprophylaxis } \\
\text { and therapy }\end{array}$} \\
\hline & & $\begin{array}{l}1 \times 10^{6} \mathrm{PFU} \\
(\mathrm{IN})\end{array}$ & & & & & & \\
\hline & & $\begin{array}{l}12 \mathrm{~h} \text { post- } \mathrm{Ab} \\
\text { infusion }\end{array}$ & & & & & & \\
\hline \multirow[t]{3}{*}{$\begin{array}{l}\text { Rogers } \\
\text { et al. (2020) } \\
\text { [58] }\end{array}$} & \multirow{3}{*}{$\begin{array}{l}n=6 \\
\text { Control } \\
\text { lgG1 } \\
\text { (Den3) \| }\end{array}$} & $\begin{array}{l}\text { SARS-CoV-2 } \\
\text { (USAWA1/ } \\
\text { 2020) }\end{array}$ & \multirow[t]{3}{*}{$\begin{array}{l}\text { Weight loss } \\
\text { (5) }\end{array}$} & \multirow{3}{*}{$\begin{array}{l}\text { No difference in } \\
\text { lung viral loads } \\
\text { control vs. low } \\
\text { dose groups }\end{array}$} & \multirow[t]{3}{*}{$\begin{array}{l}\text { NA } \\
(5)\end{array}$} & \multirow[t]{3}{*}{ NA } & \multirow[t]{3}{*}{ NA } & \\
\hline & & $\begin{array}{l}1 \times 10^{6} \mathrm{PFU} \\
(\mathrm{IN})\end{array}$ & & & & & & \\
\hline & & $\begin{array}{l}12 \mathrm{~h} \text { post-Ab } \\
\text { infusion }\end{array}$ & & & & & & \\
\hline \multirow[t]{4}{*}{$\begin{array}{l}\text { Golden } \\
\text { Syrian } \\
\text { hamsters }\end{array}$} & \multirow[t]{4}{*}{$\begin{array}{l}(n=9)) \\
4-5 \\
\text { weeks } \\
\text { (M) } \\
\text { (Donor) }\end{array}$} & $\begin{array}{l}\text { SARS-CoV-2 } \\
\text { BetaCoV/ } \\
\text { Hong Kong/ } \\
\text { VM20001061/ } \\
2020\end{array}$ & $\begin{array}{l}\text { Weight loss } \\
\text { (6) }\end{array}$ & $\begin{array}{l}\text { Upper respiratory } \\
\text { tract, nose, } \\
\text { olfactory }\end{array}$ & $\begin{array}{l}\text { Inflammatory } \\
\text { infiltrates nasal } \\
\text { turbinate } \\
\text { Progressive lung } \\
\text { consolidation ( } 5 \text { to } \\
60 \% \text { ) Mononuclear } \\
\text { cell infiltration. }\end{array}$ & $\begin{array}{l}\text { CD3 positive T } \\
\text { lymphocytes in } \\
\text { peribronchial region } \\
\text { (5) }\end{array}$ & $\begin{array}{l}\text { IgG antibody } \\
\text { response } \\
\text { against SARS- } \\
\text { CoV-2 (14) }\end{array}$ & Viral transmission \\
\hline & & & $\begin{array}{l}\text { Ruffled hair } \\
\text { coat (5) }\end{array}$ & $\begin{array}{l}\text { Neurons, } \\
\text { bronchus, lung }\end{array}$ & $\begin{array}{l}\text { No extrapulmonary } \\
\text { pathology }\end{array}$ & & & \\
\hline & & & & $\begin{array}{l}\text { Kidney, } \\
\text { duodenum }\end{array}$ & & & & \\
\hline & & $\begin{array}{l}8 \times 10^{4} \\
\mathrm{TCID}_{50}(\mathrm{IN})\end{array}$ & & & $\begin{array}{l}\text { No pathology in the } \\
\text { intestine, spleen, } \\
\text { heart, and brain }(2 \text {, } \\
5,7) \\
(2,5,7)\end{array}$ & & & \\
\hline $\begin{array}{l}\text { Sia et al. } \\
\text { (2020) [59] }\end{array}$ & $(n=9)$ & $\begin{array}{l}\text { Infection via } \\
\text { contact with } \\
\text { donor } \\
\text { hamster }\end{array}$ & $\begin{array}{l}\text { Weight loss } \\
\text { (6) }\end{array}$ & $\begin{array}{l}\text { Detectable } \\
\text { infectious viruses } \\
(9 / 9)\end{array}$ & NA & NA & $\begin{array}{l}\text { IgG antibody } \\
\text { response } \\
\text { against SARS- } \\
\text { CoV-2 (14) }\end{array}$ & \\
\hline & $4-5$ & & Ruffled hair & Day 1 post- & & & & \\
\hline
\end{tabular}


Table 4 Summary of studies using hamsters models of COVID-19 (Continued)

\begin{tabular}{|c|c|c|c|c|c|c|c|c|}
\hline $\begin{array}{l}\text { Species } \\
\text { (ref) }\end{array}$ & $\begin{array}{l}\text { Number } \\
\text { age } \\
\text { (gender) }\end{array}$ & $\begin{array}{l}\text { Virus strain } \\
\text { dose* } \\
\text { (inoculation } \\
\text { route) } \dagger\end{array}$ & $\begin{array}{l}\text { Clinical } \\
\text { signs \& } \\
\text { observation } \\
\text { duration } \\
\text { (DPI) § }\end{array}$ & $\begin{array}{l}\text { Viral } \\
\text { replication } \neq \\
\text { (DPI) }\end{array}$ & $\begin{array}{l}\text { Pathology \& } \\
\text { sacrificing date } \\
\text { (DPI) }\end{array}$ & Immune response & $\begin{array}{l}\text { Seroconversion } \\
\text { (DPI) }\end{array}$ & $\begin{array}{l}\text { Outcome } \\
\text { measures }\end{array}$ \\
\hline & $\begin{array}{l}\text { weeks } \\
\text { (M) }\end{array}$ & & $\begin{array}{l}\text { coat day (4) } \\
(14)\end{array}$ & contact & & & & \\
\hline & (Contact) & & & $\begin{array}{l}\text { No difference in } \\
\text { viral shedding } \\
\text { contact vs. donor }\end{array}$ & & & & \\
\hline \multirow[t]{3}{*}{$\begin{array}{l}\text { Syrian } \\
\text { hamster }\end{array}$} & $(n=7)$ & $\begin{array}{l}\text { SARS-CoV-2 } \\
\text { (BetaCoV/ } \\
\text { Belgium/ } \\
\text { GHB03021/ } \\
\text { 2020) }\end{array}$ & $\begin{array}{l}N A \\
(4)\end{array}$ & $\begin{array}{l}\text { Lungs, blood, } \\
\text { spleen, liver, } \\
\text { upper \& lower } \\
\text { gastrointestinal } \\
\text { tract }\end{array}$ & $\begin{array}{l}\text { Multifocal } \\
\text { necrotizing } \\
\text { bronchiolitis, }\end{array}$ & $\begin{array}{l}\text { Increased } \\
\text { inflammation- } \\
\text { related gene } \\
\text { expression }\end{array}$ & NA & $\begin{array}{l}\text { Host interferon } \\
\text { response to } \\
\text { SARS-CoV-2 }\end{array}$ \\
\hline & $\begin{array}{l}\text { Age: NA } \\
\text { (F) }\end{array}$ & \multirow{2}{*}{$\begin{array}{l}2 \times 10^{5} \\
\mathrm{TCID}_{50}(\mathrm{P} 4 \\
\text { virus) or } 2 \times \\
106 \mathrm{TCID}_{50} \\
(\mathrm{P} 6 \text { virus) (IN) }\end{array}$} & & & $\begin{array}{l}\text { Leukocyte } \\
\text { infiltration }\end{array}$ & & & \\
\hline & $\begin{array}{l}\text { Wild } \\
\text { type }\end{array}$ & & & & $\begin{array}{l}\text { Edema (4) } \\
(2,3,4)\end{array}$ & $\begin{array}{l}\text { No increase in } \\
\text { serum levels of IL-6, } \\
\text { IL-10, and IFN- } \gamma(4)\end{array}$ & & \\
\hline \multirow{3}{*}{$\begin{array}{l}\text { Hamster } \\
\text { (STAT2-/- } \\
\text { and IL28R-a } \\
\text {-/-) strains }\end{array}$} & $(n=7)$ & \multirow[t]{3}{*}{$\begin{array}{l}\text { Same as wild } \\
\text { type }\end{array}$} & \multirow[t]{3}{*}{$\begin{array}{l}\text { NA } \\
(4)\end{array}$} & \multirow{3}{*}{$\begin{array}{l}\text { Greater levels of } \\
\text { viral RNA in the } \\
\text { lung, spleen, } \\
\text { liver, blood, and } \\
\text { upper and lower } \\
\text { gastrointestinal } \\
\text { tract in STAT2-/- } \\
\text { hamster vs. WT } \\
\text { and IL28ra-/- }\end{array}$} & \multirow{3}{*}{$\begin{array}{l}\text { Lung pathology and } \\
\text { inflammation } \\
\text { decreased in (STAT2 } \\
-/-) \text { but not in } \\
\text { IL28R-a-/- hamsters } \\
(2,3,4) \\
(2,3,4)\end{array}$} & $\begin{array}{l}\text { Increased IL-6 and } \\
\text { IL-10 expression in } \\
\text { lungs }\end{array}$ & \multirow[t]{3}{*}{ NA } & \\
\hline & $\begin{array}{l}7-12 \\
\text { weeks (F) }\end{array}$ & & & & & $\begin{array}{l}\text { No increase in } \\
\text { serum levels of IL-6, }\end{array}$ & & \\
\hline & $\begin{array}{l}\text { STAT2 } \\
-/-\end{array}$ & & & & & & & \\
\hline \multirow{5}{*}{$\begin{array}{l}\text { Boudewijns } \\
\text { et al. (2020) } \\
\text { [56] }\end{array}$} & $(n=7)$ & \multirow{5}{*}{$\begin{array}{l}\text { Same as wild } \\
\text { type }\end{array}$} & \multirow{5}{*}{$\begin{array}{l}N A \\
(4)\end{array}$} & \multirow{2}{*}{$\begin{array}{l}\text { Lungs, blood, } \\
\text { spleen, liver, } \\
\text { upper, \& lower } \\
\text { gastrointestinal } \\
\text { tract }\end{array}$} & \multirow{5}{*}{$\begin{array}{l}\text { Bronchopneumonia } \\
\text { and peribronchiolar } \\
\text { inflammation }(2,3,4) \\
(2,3,4)\end{array}$} & High (MMP)-9 levels & \multirow[t]{5}{*}{ NA } & \\
\hline & $\begin{array}{l}5-7 \\
\text { weeks (F) }\end{array}$ & & & & & $\begin{array}{l}\text { In lung } \\
\text { homogenates } \\
\text { compare to WT }\end{array}$ & & \\
\hline & & & & \multirow{3}{*}{$\begin{array}{l}\text { No differences in } \\
\text { lung viral RNA } \\
\text { levels in WT, vs. } \\
\text { STAT2-/- vs. } \\
\text { IL28R-a-/- } \\
\text { hamsters }\end{array}$} & & $\begin{array}{l}\text { Increased IL-6 and } \\
\text { IL- }\end{array}$ & & \\
\hline & \multirow[t]{2}{*}{$\begin{array}{l}\text { IL28R-a } \\
-/-\end{array}$} & & & & & $\begin{array}{l}10 \text { expression in } \\
\text { lungs }\end{array}$ & & \\
\hline & & & & & & $\begin{array}{l}\text { No increase in } \\
\text { serum levels of IL-6, } \\
\text { IL-10 and IFNy (4) }\end{array}$ & & \\
\hline
\end{tabular}

${ }^{*} T C I D_{50}$ Median Tissue Culture Infectious Dose at which 50\% of the cells are infected, PFU plaque-forming unit, + IN intranasal, $\neq$ viral replication: RNA copies (PCR), and or viral antigen (immunostaining), viral particles (electron microscopy). § dpi day post-inoculation, ๆ mAb CC12.1 IP SARS-CoV-2-2specific human neutralizing monoclonal antibodies, $\| \lg G 1$ (Den3) $2 \mathrm{mg}$ of a dengue specific human IgG1

against RBD [50], were tested in these mouse models and produced a protective effect. Likewise, vaccines using viral particles expressing SARS-2-S protein [52] or an RBD-based vaccine were tested and showed protection [55].

\section{Hamster}

\section{Viral model}

Wild type Syrian hamsters and knockout hamsters for signal transducer and activator of transcription 2 (STAT2-/- lacking type I and III interferon signaling) and interleukin 28 receptors (IL28r-/- lacking IFN type III signaling) were reported as models for COVID-19. Patient isolate of SARS-CoV-2 from different sources and different passages on various cell cultures was used (Table 4). SARS-CoV-2 was administered intranasally at different titers to anesthetized hamsters. Viral transmission between hamsters was demonstrated either through direct contact or indirectly via airborne transmission.

\section{Phenotype}

The clinical manifestations included weight loss, which was consistently observed. Other clinical signs and symptoms such as rapid breathing, lethargy, ruffled furs, and hunched back posture were reported in one study [57]. The histopathological findings were variables according to the experimental models and ranged from lung consolidation to multifocal necrotizing bronchiolitis, leukocyte infiltration, and edema. STAT2-/- hamsters exhibited attenuated lung pathology as compared with IL28R-a-/- hamsters [56]. 


\section{Viral and host interaction}

The virus replicated to high titer in the upper and lower respiratory tract in most of the hamsters' models. Viral replication was detected in the blood and kidney with a low concentration (Table 4). STAT2-/- hamsters had higher titers of infectious virus in the lung, viremia, and high levels of viral RNA in the spleen, liver, and upper and lower gastrointestinal tract in comparison with wild type and IL28R-a-/- hamsters. Specific IgG antibodies against SARS-CoV-2 were documented in the sera of hamsters at different time-points from virus inoculation ranging from 7 to 21 days. Increased expression of proinflammatory and chemokine genes was demonstrated in the lungs of the SARS-CoV-2 infected animals, however with no increase in circulating levels of proteins such as TNF, interferon- $\gamma$, and IL-6.

\section{Drugs and vaccines}

Immunoprophylaxis with early convalescent serum achieved a significant decrease in viral lung load but not in lung pathology [57].

\section{Ferrets, cat, and dog Viral model and phenotype}

Ferrets, cats, and dogs were administered intranasally or intratracheally with various doses and strains of SARSCoV-2 (Table 5). Ferrets displayed elevated body temperature for several days associated with signs that differed according to the studies. These include decreased activity and appetite, sporadic cough, and no body weight loss [60-63]. No clinical signs were reported either in cats or in dogs.

\section{Histopathological changes}

Ferrets exhibited acute bronchiolitis [61, 63], with perivasculitis and vasculitis [63], but with no discernible pneumonia. Cats disclosed lesions in epithelial nasal, tracheal, and lung mucosa (Table 5).

\section{Viral and host interaction}

The virus replication and shedding were demonstrated in the upper airways and rectal swabs in ferrets and cats, but the extent to other tissues varied in ferrets from none to multiple organs, including the lung, blood, and urine. No viral RNA was detected in cats' lungs. Dogs showed RNA-positive rectal swab but none in the upper or lower airways. Viral transmission between ferrets and cats was demonstrated either through direct contact [55] or indirectly via airborne route [62].

Ferrets, cats, and dogs exhibited specific antibody response against SARS-CoV-2 [60, 62, 63]. A study of the ferret immune response to SARS-CoV-2 revealed a subdued low interferon type I and type III response that contrasts with increased chemokines and proinflammatory cytokine IL6, which is reminiscent of the human response [61].

\section{Discussion}

This systematic review of experimental animal models of SARS-CoV-2 induced- COVID-19 identified 13 peerreviewed studies and 14 preprints that reported data on nonhuman primates [37-49], mice [50-56], hamsters [56-59], ferrets [60-63], cats, and dog [63] models of COVID-19. The main findings indicate that most of the animal models could mimic many features of mild human COVID-19 with a full recovery phenotype [3]. They also revealed that older animals display relatively more severe illness than the younger ones [38, 46, 48, 52, 54], which evokes human COVID-19 [3, 6]. However, none of the animal models replicated the severe or critical patterns associated with mortality as observed in humans with COVID-19 [3].

The results of this systematic review are consistent with studies of animal models of SARS-CoV and MERS$\mathrm{CoV}$, which failed to replicate the full spectrum of humans' illness $[65,66]$. Nonetheless, several features of mild COVID-19 in humans could be mirrored. High viral titers in the upper and lower respiratory tract and lung pathology were demonstrated in both large and small animal models. The pathology encompassed mild interstitial pneumonia, consolidation, and diffuse alveolar damage, albeit localized to a small lung area, edema, hyaline membrane formation, and inflammation. SARS$\mathrm{CoV}-2$ elicited specific antibody response against various viral proteins in the sera of most of the animal models.

This systematic review revealed that none of these newly established animal models replicated the common complications of human COVID-19 such as ARDS and coagulopathy $[6,8,28-33,67,68]$. ARDS can be particularly severe and results in refractory hypoxemia requiring maximum respiratory supportive measures in the intensive care unit $[6,67,68]$. The coagulopathy can lead to severe complications such as massive pulmonary embolism, cerebrovascular stroke, and mesenteric infarction, including in younger people $[8,28,32,33]$. The pathology underlying these two complications were recently revealed by post-mortem studies disclosing diffuse alveolar damage involving the whole lung, hyaline membrane formation, and infiltration with inflammatory cells, thus leaving no air space open for ventilation $[17,18,64$, $69,70]$. It also detected the presence of diffuse and widespread thrombosis in the micro- and macro-circulation, including the pulmonary circulation compromising the lung perfusion $[17,18]$. This double hit affecting the ventilation and perfusion simultaneously underlies the intractable hypoxemia that contributed to the high mortality. None of the animal models replicated the respiratory failure, thromboembolic manifestations, and their 
Table 5 Summary of studies using ferrets, cat, and dog models of SARS-CoV-2 infection

\begin{tabular}{|c|c|c|c|c|c|c|c|c|}
\hline $\begin{array}{l}\text { Species } \\
\text { (ref) }\end{array}$ & $\begin{array}{l}\text { Number } \\
\text { age } \\
\text { (gender) }\end{array}$ & $\begin{array}{l}\text { Virus strain } \\
\text { dose* } \\
\text { (inoculation }_{\text {route)† }}\end{array}$ & $\begin{array}{l}\text { Clinical } \\
\text { signs \& } \\
\text { observation } \\
\text { duration } \\
\text { (DPI)§ }\end{array}$ & $\begin{array}{l}\text { Viral } \\
\text { replication } \neq \\
\text { (DPI) }\end{array}$ & $\begin{array}{l}\text { Pathology \& sacrificing } \\
\text { date (DPI) }\end{array}$ & $\begin{array}{l}\text { Immune } \\
\text { response }\end{array}$ & $\begin{array}{l}\text { Seroconversion } \\
\text { (DPI) }\end{array}$ & $\begin{array}{l}\text { Outcome } \\
\text { measures }\end{array}$ \\
\hline \multirow[t]{7}{*}{ Ferrets } & \multirow[t]{2}{*}{$n=12$} & \multirow{2}{*}{$\begin{array}{l}\text { NMC- } \\
\text { nCov02/ } \\
\text { Korea }\end{array}$} & \multirow{2}{*}{$\begin{array}{l}\text { Increased } \\
\text { body } \\
\text { temperature }\end{array}$} & \multirow{2}{*}{$\begin{array}{l}\text { Nose, saliva, } \\
\text { urine, and } \\
\text { feces }\end{array}$} & Acute bronchiolitis & \multirow[t]{4}{*}{ NAf } & \multirow{4}{*}{$\begin{array}{l}\text { IgG and serum- } \\
\text { neutralizing anti- } \\
\text { body response } \\
\text { against SARS- } \\
\text { CoV-2 (12) }\end{array}$} & \multirow{2}{*}{$\begin{array}{l}\text { Pathogenesis } \\
\text { of COVID-19 }\end{array}$} \\
\hline & & & & & $\begin{array}{l}\text { Infiltrates of immune } \\
\text { cells and debris (4) }\end{array}$ & & & \\
\hline & $\begin{array}{l}12-20 \\
\text { months }\end{array}$ & $10^{5.5} \mathrm{TCID}_{50}$ & $\begin{array}{l}\text { Reduced } \\
\text { activity }\end{array}$ & & \multirow[t]{2}{*}{$(4,8,12)$} & & & \multirow[t]{2}{*}{$\begin{array}{l}\text { Assess viral } \\
\text { transmission }\end{array}$} \\
\hline & $M / F$ & IN & $\begin{array}{l}\text { occasional } \\
\text { coughs } \\
(12)\end{array}$ & $\begin{array}{l}\text { Trachea, lung, } \\
\text { kidney, serum, } \\
\text { and intestine } \\
\text { (2) }\end{array}$ & & & & \\
\hline & $n=12$ & \multirow[t]{3}{*}{ Control } & \multirow{3}{*}{$\begin{array}{l}\mathrm{NO} \\
(12)\end{array}$} & \multirow[t]{3}{*}{ NO } & \multirow{3}{*}{$\begin{array}{l}\mathrm{NO} \\
(4,8,12)\end{array}$} & \multirow[t]{5}{*}{ NO } & \multirow[t]{3}{*}{ NO } & \\
\hline & $\begin{array}{l}12-20 \\
\text { months }\end{array}$ & & & & & & & \\
\hline & $\mathrm{M} / \mathrm{F}$ & & & & & & & \\
\hline \multirow[t]{2}{*}{$\begin{array}{l}\text { Kim } \\
\text { et al. } \\
(2020) \\
{[60]}\end{array}$} & $\begin{array}{l}n=6 \\
\text { (naïve } \\
\text { direct } \\
\text { contact) }\end{array}$ & $\begin{array}{l}\text { Direct } \\
\text { contact }\end{array}$ & $\begin{array}{l}\text { Increased } \\
\text { body } \\
\text { temperature } \\
\text { (12) }\end{array}$ & $\begin{array}{l}\text { All animals } \\
\text { were infected } \\
(2)\end{array}$ & (12) & & $\begin{array}{l}\text { IgG and serum- } \\
\text { neutralizing anti- } \\
\text { body response } \\
\text { against SARS- } \\
\text { CoV-2 (12) }\end{array}$ & \\
\hline & $\begin{array}{l}n=6 \\
\text { (naïve } \\
\text { indirect } \\
\text { contact) }\end{array}$ & $\begin{array}{l}\text { Indirect } \\
\text { contacts }\end{array}$ & $\begin{array}{l}\text { No increased } \\
\text { body } \\
\text { temperature } \\
(12)\end{array}$ & $\begin{array}{l}\text { Nose, feces ( } 2 \\
\text { out of } 6 \\
\text { animals) } \\
\text { (4) }\end{array}$ & (12) & & $\begin{array}{l}\text { IgG antibody } \\
\text { response against } \\
\text { SARS-CoV-2 (12) } \\
\text { Serum- } \\
\text { neutralizing } \\
\text { antibody } \\
\text { response in } 1 \text { out } \\
\text { of } 6\end{array}$ & \\
\hline \multirow{3}{*}{$\begin{array}{l}\text { Ferrets } \\
\text { Blanco- } \\
\text { Melo } \\
\text { et al. } \\
(2020) \\
{[61]}\end{array}$} & $n=6$ & $\begin{array}{l}\text { USA-WA1/ } \\
2020\end{array}$ & \multirow[t]{3}{*}{$\begin{array}{l}\text { NA } \\
(14)\end{array}$} & Nose, trachea & \multirow[t]{3}{*}{$\begin{array}{l}\text { NA } \\
(3,14)\end{array}$} & $\begin{array}{l}\text { Reduced } \\
\text { interferon type I } \\
\text { and III response }\end{array}$ & \multirow[t]{3}{*}{ NA } & \multirow[t]{3}{*}{$\begin{array}{l}\text { Host } \\
\text { interferon } \\
\text { response }\end{array}$} \\
\hline & 4 months & $5 \times 10^{4} \mathrm{PFU}$ & & $(3,7)$ & & & & \\
\hline & $\begin{array}{l}\text { Castrated } \\
\text { male }\end{array}$ & IN & & & & $\begin{array}{l}\text { Increase } \\
\text { proinflammatory } \\
\text { chemokines and } \\
\text { cytokines } \\
\text { response }\end{array}$ & & \\
\hline \multirow{9}{*}{$\begin{array}{l}\text { Ferrets } \\
\text { Richard } \\
\text { et al. } \\
(2020) \\
\text { [62] }\end{array}$} & $n=4$ & $\begin{array}{l}\text { BetaCoV/ } \\
\text { Munich/ } \\
\text { BavPat1/2020 }\end{array}$ & \multirow[t]{3}{*}{$\begin{array}{l}\text { NA } \\
(21)\end{array}$} & \multirow[t]{3}{*}{$\begin{array}{l}\text { Nose, throat, } \\
\text { rectum }\end{array}$} & \multirow[t]{3}{*}{$\begin{array}{l}\text { NA } \\
(21)\end{array}$} & \multirow[t]{3}{*}{ NA } & \multirow[t]{3}{*}{$\begin{array}{l}\text { IgG antibody } \\
\text { response against } \\
\text { SARS-CoV-2 (21) }\end{array}$} & \multirow[t]{9}{*}{$\begin{array}{l}\text { Viral } \\
\text { transmission }\end{array}$} \\
\hline & $\begin{array}{l}6 \text { months } \\
(F)\end{array}$ & $6.10^{5} \mathrm{TCID}_{50}$ & & & & & & \\
\hline & Donor & IN & & & & & & \\
\hline & $n=4$ & \multirow{3}{*}{$\begin{array}{l}6 \text { h post- } \\
\text { inoculation } \\
\text { co-housed } \\
\text { with donor }\end{array}$} & \multirow{3}{*}{$\begin{array}{l}\text { NA } \\
(21)\end{array}$} & \multirow{3}{*}{$\begin{array}{l}\text { Nose, throat, } \\
\text { rectum (1) }\end{array}$} & \multirow{3}{*}{$\begin{array}{l}\text { NA } \\
(21)\end{array}$} & NA & lgG antibody & \\
\hline & $\begin{array}{l}6 \text { months } \\
(F)\end{array}$ & & & & & & $\begin{array}{l}\text { response against } \\
\text { SARS-CoV-2 (21) }\end{array}$ & \\
\hline & $\begin{array}{l}\text { direct } \\
\text { contact }\end{array}$ & & & & & & & \\
\hline & $n=4$ & 1 dpi placed & NA & Nose, throat, & NA & NA & IgG antibody & \\
\hline & $\begin{array}{l}6 \text { months } \\
(F)\end{array}$ & $\begin{array}{l}\text { In an } \\
\text { opposite } \\
\text { cage }(10 \mathrm{~cm})\end{array}$ & $(21)$ & & (21) & & $\begin{array}{l}\text { response against } \\
\text { SARS-CoV-2 (21) }\end{array}$ & \\
\hline & $\begin{array}{l}\text { Indirect } \\
\text { contact }\end{array}$ & of donor & & & & & & \\
\hline Ferrets & $n=10$ & $\begin{array}{l}\text { SARS-CoV-2 } \\
/ \text { F13/ }\end{array}$ & Fever & $\begin{array}{l}\text { Nose, throat, } \\
\text { and rectum }\end{array}$ & $\begin{array}{l}\text { Severe } \\
\text { lymphoplasmacytic, }\end{array}$ & & $\begin{array}{l}\text { IgG antibody } \\
\text { response against }\end{array}$ & $\begin{array}{l}\text { Pathogenesis } \\
\text { of COVID-19 }\end{array}$ \\
\hline
\end{tabular}


Table 5 Summary of studies using ferrets, cat, and dog models of SARS-CoV-2 infection (Continued)

\begin{tabular}{|c|c|c|c|c|c|c|c|c|}
\hline $\begin{array}{l}\text { Species } \\
\text { (ref) }\end{array}$ & $\begin{array}{l}\text { Number } \\
\text { age } \\
\text { (gender) }\end{array}$ & $\begin{array}{l}\text { Virus strain } \\
\text { dose* } \\
\text { (inoculation } \\
\text { route)† }\end{array}$ & $\begin{array}{l}\text { Clinical } \\
\text { signs \& } \\
\text { observation } \\
\text { duration } \\
(\mathrm{DPI}) \S \\
\end{array}$ & $\begin{array}{l}\text { Viral } \\
\text { replication } \neq \\
\text { (DPI) }\end{array}$ & $\begin{array}{l}\text { Pathology \& sacrificing } \\
\text { date (DPI) }\end{array}$ & $\begin{array}{l}\text { Immune } \\
\text { response }\end{array}$ & $\begin{array}{l}\text { Seroconversion } \\
\text { (DPI) }\end{array}$ & $\begin{array}{l}\text { Outcome } \\
\text { measures }\end{array}$ \\
\hline & & $\begin{array}{l}\text { environment/ } \\
\text { 2020/Wuhan }\end{array}$ & & $\begin{array}{l}\text { (low titer) (4- } \\
\text { 8) }\end{array}$ & perivasculitis & & SARS-CoV-2 (13) & \\
\hline & $\begin{array}{l}3-4 \\
\text { months } \\
\text { F }\end{array}$ & & $\begin{array}{l}\text { Loss of } \\
\text { appetite } \\
(20)\end{array}$ & & Vasculitis & NA & & \\
\hline & & $\begin{array}{l}\text { SARS-CoV2/ } \\
\text { CTan/ } \\
\text { human/2020/ } \\
\text { Wuhan] }\end{array}$ & & & $\begin{array}{l}\text { Increased type II } \\
\text { pneumocytes, } \\
\text { macrophages, and } \\
\text { neutrophils in the } \\
\text { alveolar septa and } \\
\text { alveolar lumen. }\end{array}$ & & & \\
\hline & & $10^{5} \mathrm{PFU}$ & & & Mild peribronchitis (13) & & & \\
\hline & & IN & & & $(4,20)$ & & & \\
\hline & $n=8$ & $\begin{array}{l}\text { SARS-CoV2/ } \\
\text { CTan/ } \\
\text { human/2020/ } \\
\text { Wuhan] }\end{array}$ & $\begin{array}{l}\text { NA } \\
(14)\end{array}$ & $\begin{array}{l}\text { Nose, throat } \\
(2-8)\end{array}$ & $\begin{array}{l}\text { NA } \\
(2,4,8,14)\end{array}$ & NA & NA & \\
\hline & $\begin{array}{l}3-4 \\
\text { months }\end{array}$ & $10^{5} \mathrm{PFU}$ & & & & & & \\
\hline & $\mathrm{F}$ & IT & & & & & & \\
\hline \multirow[t]{8}{*}{ Cats } & $n=10$ & $\begin{array}{l}\text { SARS-CoV-2 } \\
\text { /CTan/ } \\
\text { human/2020/ } \\
\text { Wuhan }\end{array}$ & $\begin{array}{l}\text { NA } \\
(20)\end{array}$ & \multirow[t]{4}{*}{$\begin{array}{l}\text { Nose, soft } \\
\text { palate, tonsil, } \\
\text { trachea, lungs, } \\
\text { and small } \\
\text { intestines. }\end{array}$} & \multirow[t]{4}{*}{$\begin{array}{l}\text { NA } \\
(3,6,10,20)\end{array}$} & \multirow[t]{4}{*}{ NA } & \multirow[t]{4}{*}{$\begin{array}{l}\text { IgG antibody } \\
\text { response against } \\
\text { SARS-CoV-2 (10) }\end{array}$} & \\
\hline & $\begin{array}{l}6-9 \\
\text { months }\end{array}$ & $10^{5} \mathrm{PFU}$ & & & & & & \\
\hline & $M \backslash F$ & IN & & & & & & \\
\hline & Sub-adult & & & & & & & \\
\hline & $n=10$ & $\begin{array}{l}\text { SARS-CoV-2 } \\
\text { /CTan/ } \\
\text { human/2020/ } \\
\text { Wuhan }\end{array}$ & $\begin{array}{l}\text { One cat died } \\
(3) \\
(12)\end{array}$ & \multirow[t]{4}{*}{$\begin{array}{l}\text { Nose, soft } \\
\text { palate, tonsil, } \\
\text { trachea, lungs, } \\
\text { and small } \\
\text { intestines. }\end{array}$} & \multirow[t]{4}{*}{$\begin{array}{l}\text { Extensive nasal, tonsil, } \\
\text { tracheal, lung, and small } \\
\text { intestine epithelial } \\
\text { mucosal lesions ( } 3) \\
(3,6,11,12)\end{array}$} & \multirow[t]{4}{*}{ NA } & \multirow[t]{4}{*}{$\begin{array}{l}\text { IgG antibody } \\
\text { response against } \\
\text { SARS-CoV-2 (10) }\end{array}$} & \\
\hline & $\begin{array}{l}70-100 \\
\text { days }\end{array}$ & $10^{5} \mathrm{PFU}$ & & & & & & \\
\hline & $M / F$ & IN & & & & & & \\
\hline & Juvenile & & & & & & & \\
\hline \multirow[t]{3}{*}{ Dogs } & $n=5$ & $\begin{array}{l}\text { SARS-CoV-2- } \\
\text { 2/CTan/ } \\
\text { human/2020/ } \\
\text { Wuhan }\end{array}$ & NA & Rectum (2/5) & NA & NA & \multirow[t]{3}{*}{$\begin{array}{l}\text { IgG antibody } \\
\text { response against } \\
\text { SARS-CoV-2 (14) }\end{array}$} & \\
\hline & 3-month & $10^{5} \mathrm{PFU}$ & & & & & & \\
\hline & & IN, & & & & & & \\
\hline \multirow{3}{*}{$\begin{array}{l}\text { Shi et al. } \\
(2020) \\
{[63]}\end{array}$} & $n=2$ & \multirow{3}{*}{$\begin{array}{l}\text { Exposed to } \\
\text { donor }\end{array}$} & \multirow[t]{3}{*}{ NA } & \multirow[t]{3}{*}{ No } & \multirow[t]{3}{*}{ NA } & \multirow[t]{3}{*}{ NA } & \multirow[t]{3}{*}{ No } & \\
\hline & 3 month & & & & & & & \\
\hline & Beagles & & & & & & & \\
\hline
\end{tabular}

${ }^{*} T C I D_{50}$ Median Tissue Culture Infectious Dose at which 50\% of the cells are infected, PFU plaque-forming unit, $+I T$ intratracheal, IN intranasal, $C J$ intraconjunctival, OC ocular, IG intragastric, PO per oral, IP intraperitoneal, ‡ viral replication RNA copies (PCR), viral antigen (immunostaining), viral particles (electron microscopy), § dpi day post-inoculation 
pathological expression, hence, indicating that a wide gap separates the animal models from the full spectrum of COVID-19 in humans.

The mechanisms of the lung injury and coagulopathy are not well understood, although several known pathways were postulated including cytokine storm leading to upregulation of tissue factor $[5,9,24]$, activation/injury of the endothelium infected by the virus [30, 67, 71], complement activation [72], alveolar hypoxia promoting thrombosis [73], and autoantibodies against phospholipid and lupus anticoagulant $[74,75]$ modulating the hemostasis and coagulation cascade directly. Hence, the development of animal models that replicate the dysregulation of the inflammation and coagulation could be important, as these would allow the deciphering of the intimate mechanisms at play. This, in turn, may aid in identifying therapeutic targets and the testing of immunotherapy, anticoagulation, and thrombolytic interventions and thereby may improve the outcome.

Both antiviral and vaccine therapies were tested in rhesus macaques and mice infected with SARS-CoV-2 [4042]. The antiviral drug stopped the viral replication and improved the pneumonitis [42, 55]. The vaccines induced an increase in titers of neutralizing antibodies in the sera that correlated with the decrease of viral replication and prevented the lung pathology [39-41]. These results represent a substantial proof of the concept of antiviral or vaccine efficacy against SARS-CoV-2 in animal models. However, because of the lack of overt clinical illness, the rapid clearance of the virus, and spontaneous improvement of the pneumonitis without lethality, the models do not permit the full assessment of the duration of the protection of the vaccines, or the effect of antiviral therapy on survival.

Since the emergence of SARS-CoV infection in 2003 [76], followed by the MERS-CoV in 2012 [77], and now with COVID-19, researchers have not been able to develop a model of coronavirus infection that reproduces the severity and lethality seen in humans $[65,66]$. One of the well-known reasons lies in the difference of ACE2 receptor binding domain structure across species [78]. Human and primates have conserved a comparable structure that allows binding with high affinity to the SARS-CoV-2 [78]. The hamsters, ferrets, and cats maintained an intermediate affinity, while mice exhibit very low affinity [78]. The latter explains why wild-type mouse does not support SARS-CoV-2 replication, and hence, the necessity to create a chimera that expresses human ACE-2, to enable the use of this species as a model of COVID-19 [50]. More recently, a study applying single-cell RNA sequencing to nonhuman primate uncovered another explanation that may underlie the difference between nonhuman primates and humans in expressing the complex phenotype of COVID-19 [79].
The study reveals that the cellular expression and distribution of ACE2 and TMPRSS2 which are essential for virus entry in the cells and its spread inside the body differ in the lung, liver, and kidney between the two species. ACE2 expression was found lower in pneumocytes type II and higher in ciliated cells in nonhuman primate lung as compared to humans [40]. This is particularly significant as type II pneumocytes are critical targets of SARS-CoV-2 in humans and the pathogenesis of lung injury/damage. Finally, the innate immune response including the defense system against viruses diverged during evolution both at the transcriptional levels and cellular levels, which may also explain why the SARSCoV-2 hardly progresses in these animals outside the respiratory system [80]. Taken together, these fundamental differences represent a real challenge to the successful development of an animal model that reproduces human COVID-19.

This systematic review has a few limitations. First, it is the high number of preprints included in this study that have not been peer-reviewed. Second, the animal models from the same species were difficult to compare across studies, as they used different viral strain, inoculum size, route of administration, and timing of tissue collection.

\section{Conclusion: failure to reproduce a severe form of human COVID-19}

This systematic review revealed that animal models of COVID19 mimic mild human COVID-19, but not the severe form COVID-19 associated with mortality. It also disclosed the knowledge generated by these models of COVID-19 including viral dynamic and transmission, pathogenesis, and testing of therapy and vaccines. Likewise, the study underlines the distinct advantages and limitations of each model, which should be considered when designing studies, interpreting pathogenic mechanisms, or extrapolating therapy or vaccines results to humans. Finally, harmonization of animal research protocols to generate results that are consistent, reproducible, and comparable across studies is needed.

\section{Supplementary information}

Supplementary information accompanies this paper at https://doi.org/10. 1186/s13054-020-03304-8.

Additional file 1. Data extraction, appraisal, and outcome.

Additional file 2. List of excluded studies.

\section{Abbreviations}

COVID-19: Coronavirus disease 2019; SARS-CoV-2: Severe acute respiratory syndrome-coronavirus 2; ARDS: Acute respiratory distress syndrome; MOSD: Multiple organ dysfunction/failure; ACE: Angiotensin-converting enzyme; TMPRSS: Transmembrane serine protease; PRISMA: Preferred

Reporting Items for Systematic Reviews and Meta-analysis; hACE2: Chimeric mouse expressing human angiotensin-converting enzyme 2; IFN: Interferon; STAT2: Signal transducer and activator of transcription 2; Ces1c: Serum 
esterase; RBD: Receptor-binding domain; MERS-CoV: Middle East Respiratory Syndrome

\section{Acknowledgements}

Not applicable

\section{Authors' contributions}

A.B. designed the study, analysis of the data, and writing the manuscript. S.E., M.A., and B.A. acquisition of the data, selection of studies, appraisal of the literature, and contributed to the writing of the manuscript. The authors read and approved the final manuscript.

\section{Funding}

There was no funding source for this study.

\section{Availability of data and materials}

All data generated or analyzed during this study are included in this published article [and its supplementary information files].

\section{Ethics approval and consent to participate}

Not applicable

\section{Consent for publication}

Not applicable

\section{Competing interests}

The authors declare that they have no competing interests.

\section{Received: 13 July 2020 Accepted: 21 September 2020}

\section{Published online: 06 October 2020}

\section{References}

1. Zhou $P$, Yang $X L$, Wang XG, Hu B, Zhang L, Zhang W, Si HR, Zhu Y, Li B, Huang $C L$, et al. A pneumonia outbreak associated with a new coronavirus of probable bat origin. Nature. 2020;579(7798):270-3.

2. Zhu N, Zhang D, Wang W, Li X, Yang B, Song J, Zhao X, Huang B, Shi W, Lu $R$, et al. A novel coronavirus from patients with pneumonia in China, 2019. N Engl J Med. 2020;382(8):727-33

3. Wu Z, McGoogan JM. Characteristics of and important lessons from the coronavirus disease 2019 (COVID-19) outbreak in China: summary of a report of 72314 cases from the Chinese Center for Disease Control and Prevention. JAMA. 2020;323(13):1239-2.

4. Zhang $X$, Tan Y, Ling Y, Lu G, Liu F, Yi Z, Jia X, Wu M, Shi B, Xu S, et al. Viral and host factors related to the clinical outcome of COVID-19. Nature. 2020; 583(7816):437-40.

5. Chen G, Wu D, Guo W, Cao Y, Huang D, Wang H, Wang T, Zhang X, Chen $\mathrm{H}, \mathrm{Yu} \mathrm{H}$, et al. Clinical and immunological features of severe and moderate coronavirus disease 2019. J Clin Invest. 2020;130(5):2620-9.

6. Grasselli G, Zangrillo A, Zanella A, Antonelli M, Cabrini L, Castelli A, Cereda D, Coluccello A, Foti G, Fumagalli R, et al. Baseline characteristics and outcomes of 1591 patients infected with SARS-CoV-2 admitted to ICUs of the Lombardy Region, Italy. JAMA. 2020;323(16):1574-81.

7. Guo T, Fan Y, Chen M, Wu X, Zhang L, He T, Wang H, Wan J, Wang X, Lu Z Cardiovascular implications of fatal outcomes of patients with coronavirus disease 2019 (COVID-19). JAMA Cardiol. 2020:5(7):811-8.

8. Helms J, Tacquard C, Severac F, Leonard-Lorant I, Ohana M, Delabranche X, Merdji H, Clere-Jehl R, Schenck M, Fagot Gandet F, et al. High risk of thrombosis in patients with severe SARS-CoV-2 infection: a multicenter prospective cohort study. Intensive Care Med. 2020:46(6):1-10.

9. Huang C, Wang Y, Li X, Ren L, Zhao J, Hu Y, Zhang L, Fan G, Xu J, Gu X, et al. Clinical features of patients infected with 2019 novel coronavirus in Wuhan, China. Lancet. 2020;395(10223):497-506.

10. Wrapp D, Wang N, Corbett KS, Goldsmith JA, Hsieh CL, Abiona O, Graham BS, McLellan JS. Cryo-EM structure of the 2019-nCoV spike in the prefusion conformation. Science. 2020;367(6483):1260-3.

11. Hoffmann M, Kleine-Weber H, Schroeder S, Krüger N, Herrler T, Erichsen S, Schiergens TS, Herrler G, Wu NH, Nitsche A, et al. SARS-CoV-2 cell entry depends on ACE2 and TMPRSS2 and is blocked by a clinically proven protease inhibitor. Cell. 2020;181(2):271-280.e278.

12. Sungnak $W$, Huang $N$, Bécavin C, Berg M, Queen R, Litvinukova M, TalaveraLópez C, Maatz H, Reichart D, Sampaziotis F, et al. SARS-CoV-2 entry factors are highly expressed in nasal epithelial cells together with innate immune genes. Nat Med. 2020;26(5):681-7.

13. Muus $C$, Luecken MD, Eraslan G, Waghray A, Heimberg G, Sikkema L, Kobayashi Y, Vaishnav ED, Subramanian A, Smilie C, et al. Integrated analyses of single-cell atlases reveal age, gender, and smoking status associations with cell type-specific expression of mediators of SARS-CoV-2 viral entry and highlights inflammatory programs in putative target cells. bioRxiv. https://doi.org/10.1101/2020.04.19.049254.

14. Ziegler CGK, Allon SJ, Nyquist SK, Mbano IM, Miao VN, Tzouanas CN, Cao Y, Yousif AS, Bals J, Hauser BM, et al. SARS-CoV-2 receptor ACE2 is an interferon-stimulated gene in human airway epithelial cells and is detected in specific cell subsets across tissues. Cell. 2020;181(5):1016-1035.e1019.

15. Li C, Ji F, Wang L, Wang L, Hao J, Dai M, Liu Y, Pan X, Fu J, Li L, et al. Asymptomatic and human-to-human transmission of SARS-CoV-2 in a 2family cluster, Xuzhou, China. Emerg Infect Dis. 2020; 26(7):1626-8.

16. Rothe C, Schunk M, Sothmann P, Bretzel G, Froeschl G, Wallrauch C, Zimmer T, Thiel V, Janke C, Guggemos W, et al. Transmission of 2019-nCoV infection from an asymptomatic contact in Germany. N Engl J Med. 2020;382(10): 970-1.

17. Bradley BT, Maioli H, Johnston R, Chaudhry I, Fink SL, Xu H, Najafian B, Marshall D, Lacy JM, Williams T, et al. Histopathology and ultrastructural findings of fatal COVID-19 infections. medRxiv. https://doi.org/10.1101/2020. 04.17.20058545.

18. Wichmann D, Sperhake JP, Lütgehetmann M, Steurer S, Edler C, Heinemann A, Heinrich F, Mushumba H, Kniep I, Schröder AS, et al. Autopsy findings and venous thromboembolism in patients with COVID-19. Ann Intern Med 2020;173(4):268-77.

19. Horton R. Offline: a global health crisis? No, something far worse. Lancet. 2020;395(10234):1410.

20. Global death from COVID-19. COVID-19 Map - John Hopkins Coronavirus Resource Center. https://coronavirus.jhu.edu/map.html. Accessed 5 July 2020

21. Zhou F, Yu T, Du R, Fan G, Liu Y, Liu Z, Xiang J, Wang Y, Song B, Gu X, et al. Clinical course and risk factors for mortality of adult inpatients with COVID19 in Wuhan, China: a retrospective cohort study. Lancet. 2020;395(10229): 1054-62.

22. Liu Y, Yan LM, Wan L, Xiang TX, Le A, Liu JM, Peiris M, Poon LLM, Zhang W. Viral dynamics in mild and severe cases of COVID-19. Lancet Infect Dis. 2020;20(6):656-7.

23. Thevarajan I, Nguyen THO, Koutsakos M, Druce J, Caly L, van de Sandt CE, Jia X, Nicholson S, Catton M, Cowie B, et al. Breadth of concomitant immune responses prior to patient recovery: a case report of non-severe COVID-19. Nat Med. 2020;26(4):453-5.

24. Zhou Z, Ren L, Zhang L, Zhong J, Xiao Y, Jia Z, Guo L, Yang J, Wang C, Jiang $S$, et al. Heightened innate immune responses in the respiratory tract of COVID-19 patients. Cell Host Microbe. 2020;27(6):883-90.e882.

25. Liu B, Han J, Cheng X, Yu L, Zhang L, Wang W, Ni L, Wei C, Huang Y, Cheng Z. Persistent SARS-CoV-2 presence is companied with defects in adaptive immune system in non-severe COVID-19 patients. medRxiv. https://doi.org/ 10.1101/2020.03.26.20044768

26. Zheng M, Gao Y, Wang G, Song G, Liu S, Sun D, Xu Y, Tian Z. Functional exhaustion of antiviral lymphocytes in COVID-19 patients. Cell Mol Immunol. 2020:17(5):533-5.

27. Tan L, Wang Q, Zhang D, Ding J, Huang Q, Tang YQ, Wang Q, Miao H. Lymphopenia predicts disease severity of COVID-19: a descriptive and predictive study. Signal Transduct Target Ther. 2020;5(1):33.

28. Grillet F, Behr J, Calame P, Aubry S, Delabrousse E. Acute pulmonary embolism associated with COVID-19 pneumonia detected with pulmonary CT angiography. Radiology. 2020;296(3):E186-8..

29. Klok FA, Kruip M, van der Meer NJM, Arbous MS, Gommers D, Kant KM, Kaptein FHJ, van Paassen J, Stals MAM, Huisman MV, et al. Incidence of thrombotic complications in critically ill ICU patients with COVID-19. Thromb Res. 2020;191:145-7.

30. Poor HD, Ventetuolo CE, Tolbert T, Chun G, Serrao G, Zeidman A, Dangayach NS, Olin J, Kohli-Seth R, Powell CA. COVD-19 critical illness pathophysiology driven by diffuse pulmonary thrombi and pulmonary endothelial dysfunction responsive to thrombolysis. medRxiv.. https://doi.org/10.1101/2020.04.17.20057125.

31. Whyte CS, Morrow GB, Mitchell JL, Chowdary P, Mutch NJ. Fibrinolytic abnormalities in acute respiratory distress syndrome (ARDS) and versatility of thrombolytic drugs to treat COVID-19. J Thromb Haemost. 2020;18(7): 1548-55. 
32. Bhayana R, Som A, Li MD, Carey DE, Anderson MA, Blake MA, Catalano O, Gee MS, Hahn PF, Harisinghani M, et al. Abdominal imaging findings in COVID-19: preliminary observations. Radiology. 2020;297(1):E207-15.

33. Oxley TJ, Mocco J, Majidi S, Kellner CP, Shoirah H, Singh IP, De Leacy RA, Shigematsu T, Ladner TR, Yaeger KA, et al. Large-vessel stroke as a presenting feature of COVID-19 in the young. N Engl J Med. 2020;382(20):e60.

34. Tang N, Bai H, Chen X, Gong J, Li D, Sun Z. Anticoagulant treatment is associated with decreased mortality in severe coronavirus disease 2019 patients with coagulopathy. J Thromb Haemost. 2020;18(5):1094-9.

35. Lakdawala SS, Menachery VD. The search for a COVID-19 animal model. Science. 2020;368(6494):942-3.

36. Moher D, Liberati A, Tetzlaff J, Altman DG. Preferred reporting items for systematic reviews and meta-analyses: the PRISMA statement. PLoS Med 2009;6(7):e1000097.

37. Munster VJ, Feldmann F, Williamson BN, van Doremalen N, Pérez-Pérez L, Schulz J, Meade-White K, Okumura A, Callison J, Brumbaugh B, et al. Respiratory disease in rhesus macaques inoculated with SARS-CoV-2. Nature. 2020;585(7824):268-272.

38. Yu P, Qi F, Xu Y, Li F, Liu P, Liu J, Bao L, Deng W, Gao H, Xiang Z, et al. Agerelated rhesus macaque models of COVID-19. Anim Models Exp Med. 2020; 3(1):93-7.

39. Yu J, Tostanoski LH, Peter L, Mercado NB, McMahan K, Mahrokhian SH, Nkolola JP, Liu J, Li Z, Chandrashekar A. DNA vaccine protection against SARS-CoV-2 in rhesus macaques. Science. 2020;369(6505):806-811.

40. van Doremalen N, Lambe T, Spencer A, Belij-Rammerstorfer S, Purushotham JN, Port JR, Avanzato V, Bushmaker T, Flaxman A, Ulaszewska M, et al. ChAdOx1 nCoV-19 vaccination prevents SARS-CoV-2 pneumonia in rhesus macaques. bioRxiv. https://doi.org/10.1101/2020.05.13.093195.

41. Gao Q, Bao L, Mao H, Wang L, Xu K, Yang M, Li Y, Zhu L, Wang N, Lv Z, et al. Development of an inactivated vaccine candidate for SARS-CoV-2. Science 2020:369(6499):77-81.

42. Williamson BN, Feldmann F, Schwarz B, Meade-White K, Porter DP, Schulz J, Doremalen Nv, Leighton I, Yinda CK, Pérez-Pérez L, et al. Clinical benefit of remdesivir in rhesus macaques infected with SARS-CoV-2. bioRxiv. https:// doi.org/10.1101/2020.04.15.043166.

43. Chandrashekar A, Liu J, Martinot AJ, McMahan K, Mercado NB, Peter L, Tostanoski LH, Yu J, Maliga Z, Nekorchuk M, et al. SARS-CoV-2 infection protects against rechallenge in rhesus macaques. Science. 2020;369(6505): 812-17

44. Bao L, Deng W, Gao H, Xiao C, Liu J, Xue J, Lv Q, Liu J, Yu P, Xu Y, et al. Lack of reinfection in rhesus macaques infected with SARS-CoV-2. bioRxiv. https://doi.org/10.1101/2020.03.13.990226.

45. Deng W, Bao L, Gao H, Xiang Z, Qu Y, Song Z, Gong S, Liu J, Liu J, Yu P, et al. Ocular conjunctival inoculation of SARS-CoV-2 can cause mild COVID-19 in Rhesus macaques. bioRxiv. https://doi.org/10.1101/2020.03.13.990036.

46. Lu S, Zhao Y, Yu W, Yang Y, Gao J, Wang J, Kuang D, Yang M, Yang J, Ma C, et al. Comparison of SARS-CoV-2 infections among 3 species of non-human primates. bioRxiv. https://doi.org/10.1101/2020.04.08.031807

47. Finch CL, Crozier I, Lee JH, Byrum R, Cooper TK, Liang J, Sharer K, Solomon J, Sayre PJ, Kocher G, et al. Characteristic and quantifiable COVID-19-like abnormalities in CT- and PET/CT-imaged lungs of SARS-CoV-2-infected crabeating macaques. bioRxiv. https://doi.org/10.1101/2020.05.14.096727.

48. Rockx B, Kuiken T, Herfst S, Bestebroer T, Lamers MM, Oude Munnink BB, de Meulder D, van Amerongen G, van den Brand J, Okba NMA, et al. Comparative pathogenesis of COVID-19, MERS, and SARS in a nonhuman primate model. Science. 2020;368(6494):1012-5.

49. Woolsey C, Borisevich V, Prasad AN, Agans KN, Deer DJ, Dobias NS, Heymann JC, Foster SL, Levine CB, Medina L, et al. Establishment of an African green monkey model for COVID-19. bioRxiv. https://doi.org/10.1101/ 2020.05.17.100289.

50. Bao L, Deng W, Huang B, Gao H, Liu J, Ren L, Wei Q, Yu P, Xu Y, Qi F, et al. The pathogenicity of SARS-CoV-2 in hACE2 transgenic mice. Nature. 2020; 583(7818):830-3.

51. Li W, Drelich A, Martinez DR, Gralinski L, Chen C, Sun Z, Schäfer A, Leist SR, Liu X, Zhelev D, et al. Rapid selection of a human monoclonal antibody that potently neutralizes SARS-CoV-2 in two animal models. bioRxiv. https://doi. org/10.1101/2020.05.13.093088.

52. Dinnon KH, Leist SR, Schäfer A, Edwards CE, Martinez DR, Montgomery SA, West A, Yount BL, Hou YJ, Adams LE, et al. A mouse-adapted SARS-CoV-2 model for the evaluation of COVID-19 medical countermeasures. bioRxiv. https://doi.org/10.1101/2020.05.06.081497.
53. Lv H, Wu NC, Tsang OT, Yuan M, Perera R, Leung WS, So RTY, Chan JMC, Yip GK, Chik TSH, et al. Cross-reactive antibody response between SARS-CoV-2 and SARS-CoV infections. Cell Rep. 2020;31(9):107725.

54. Gu H, Chen $Q$, Yang G, He L, Fan H, Deng Y-Q, Wang Y, Teng Y, Zhao Z, Cui Y, et al. Rapid adaptation of SARS-CoV-2 in BALB/c mice: novel mouse model for vaccine efficacy. bioRxiv. https://doi.org/10.1101/2020.05.02.073411.

55. Pruijssers AJ, George AS, Schäfer A, Leist SR, Gralinksi LE, Dinnon KH, Yount BL, Agostini ML, Stevens LJ, Chappell JD, et al. Remdesivir potently inhibits SARS-COV-2 in human lung cells and chimeric SARS-CoV expressing the SARS-CoV-2 RNA polymerase in mice. bioRxiv. https://doi.org/10.1101/2020. 04.27.064279.

56. Boudewijns R, Thibaut HJ, Kaptein SJF, Li R, Vergote V, Seldeslachts L, De Keyzer C, Sharma S, Jansen S, Weyenbergh JV, et al. STAT2 signaling as double-edged sword restricting viral dissemination but driving severe pneumonia in SARS-CoV-2 infected hamsters. bioRxiv. https://doi.org/10. 1101/2020.04.23.056838.

57. Chan JF, Zhang AJ, Yuan S, Poon VK, Chan CC, Lee AC, Chan WM, Fan Z, Tsoi HW, Wen L, Liang R, Cao J, Chen Y, Tang K, Luo C, Cai JP, Kok KH, Chu H, Chan KH, Sridhar S, Chen Z, Chen H, To KK, Yuen KY. Simulation of the clinical and pathological manifestations of coronavirus disease 2019 (COVID-19) in golden Syrian hamster model: implications for disease pathogenesis and transmissibility. Clin Infect Dis. 2020:ciaa325. https:/doi.org/10.1093/cid/ciaa325.

58. Rogers TF, Zhao F, Huang D, Beutler N, Burns A, He W-t, Limbo O, Smith C, Song G, Woehl j, et al. Rapid isolation of potent SARS-CoV-2 neutralizing antibodies and protection in a small animal model. bioRxiv. https://doi.org/ 10.1101/2020.05.11.088674

59. Sia SF, Yan L-M, Chin AWH, Fung K, Choy K-T, Wong AYL, Kaewpreedee P, Perera RAPM, Poon LLM, Nicholls JM, et al. Pathogenesis and transmission of SARS-CoV-2 in golden hamsters. Nature. 2020;583(7818):834-8.

60. Kim Yl, Kim SG, Kim SM, Kim EH, Park SJ, Yu KM, Chang JH, Kim EJ, Lee S, Casel MAB, et al. Infection and rapid transmission of SARS-CoV-2 in ferrets. Cell Host Microbe. 2020;27(5):704-709.e702.

61. Blanco-Melo D, Nilsson-Payant BE, Liu WC, Uhl S, Hoagland D, Møller R, Jordan TX, Oishi K, Panis M, Sachs D, et al. Imbalanced host response to SARS-CoV-2 drives development of COVID-19. Cell. 2020;181(5):1036-1045.e1039.

62. Richard M, Kok A, de Meulder D, Bestebroer TM, Lamers MM, Okba NMA, van Vlissingen MF, Rockx B, Haagmans BL, Koopmans MPG, et al. SARS-CoV2 is transmitted via contact and via the air between ferrets. bioRxiv. https:// doi.org/10.1101/2020.04.16.044503.

63. Shi J, Wen Z, Zhong G, Yang H, Wang C, Huang B, Liu R, He X, Shuai L, Sun $Z$, et al. Susceptibility of ferrets, cats, dogs, and other domesticated animals to SARS-coronavirus 2. Science. 2020;368(6494):1016-20.

64. Hanley B, Lucas SB, Youd E, Swift B, Osborn M. Autopsy in suspected COVID-19 cases. J Clin Pathol. 2020;73(5):239-42.

65. Subbarao K, Roberts A. Is there an ideal animal model for SARS? Trends Microbiol. 2006;14(7):299-303.

66. Sutton TC, Subbarao K. Development of animal models against emerging coronaviruses: from SARS to MERS coronavirus. Virology. 2015;479-480:247-58.

67. Ackermann M, Verleden SE, Kuehnel M, Haverich A, Welte T, Laenger F, Vanstapel A, Werlein C, Stark H, Tzankov A, et al. Pulmonary vascular endothelialitis, thrombosis, and angiogenesis in COVID-19. N Engl J Med. 2020;383(2):120-8

68. Marini JJ, Gattinoni L. Management of COVID-19 respiratory distress. JAMA. 2020;323(22):2329-30.

69. Xu Z, Shi L, Wang Y, Zhang J, Huang L, Zhang C, Liu S, Zhao P, Liu H, Zhu L, et al. Pathological findings of COVID-19 associated with acute respiratory distress syndrome. Lancet Respir Med. 2020:8(4):420-2.

70. Nicholls JM, Poon LL, Lee KC, Ng WF, Lai ST, Leung CY, Chu CM, Hui PK, Mak KL, Lim W, et al. Lung pathology of fatal severe acute respiratory syndrome. Lancet. 2003;361(9371):1773-8.

71. Varga Z, Flammer AJ, Steiger P, Haberecker M, Andermatt R, Zinkernagel AS, Mehra MR, Schuepbach RA, Ruschitzka F, Moch H. Endothelial cell infection and endotheliitis in COVID-19. Lancet. 2020;395(10234):1417-8.

72. Mulvey JJ, Magro CM, Ma LX, Nuovo GJ, Baergen RN. Analysis of complement deposition and viral RNA in placentas of COVID-19 patients. Ann Diagn Pathol. 2020;46:151530.

73. Gupta N, Zhao YY, Evans CE. The stimulation of thrombosis by hypoxia. Thromb Res. 2019:181:77-83.

74. Zhang Y, Xiao M, Zhang S, Xia P, Cao W, Jiang W, Chen H, Ding X, Zhao H,

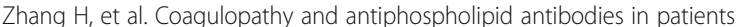
with COVID-19. N Engl J Med. 2020;382(17):e38. 
75. Bowles L, Platton S, Yartey N, Dave M, Lee K, Hart DP, MacDonald V, Green L, Sivapalaratnam S, Pasi KJ, et al. Lupus anticoagulant and abnormal coagulation tests in patients with COVID-19. N Engl J Med. 2020;383(3):288-90.

76. Lee N, Hui D, Wu A, Chan P, Cameron P, Joynt GM, Ahuja A, Yung MY, Leung $C B$, To KF, et al. A major outbreak of severe acute respiratory syndrome in Hong Kong. N Engl J Med. 2003;348(20):1986-94.

77. Zaki AM, van Boheemen S, Bestebroer TM, Osterhaus ADME, Fouchier RAM. Isolation of a novel coronavirus from a man with pneumonia in Saudi Arabia. N Engl J Med. 2012;367(19):1814-20.

78. Damas J, Hughes GM, Keough KC, Painter CA, Persky NS, Corbo M, Hiller M, Koepfli KP, Pfenning AR, Zhao H, et al. Broad host range of SARS-CoV-2 predicted by comparative and structural analysis of ACE2 in vertebrates. bioRxiv. https://doi.org/10.1101/2020.04.16.045302.

79. Han L, Wei X, Liu C, Volpe G, Wang Z, Pan T, Yuan Y, Lei Y, Lai Y, Ward H, et al. Single-cell atlas of a non-human primate reveals new pathogenic mechanisms of COVID-19. bioRxiv. https://doi.org/10.1101/2020.04.10. 022103.

80. Hagai T, Chen X, Miragaia RJ, Rostom R, Gomes T, Kunowska N, Henriksson J, Park J-E, Proserpio V, Donati G, et al. Gene expression variability across cells and species shapes innate immunity. Nature. 2018;563(7730):197-202.

\section{Publisher's Note}

Springer Nature remains neutral with regard to jurisdictional claims in published maps and institutional affiliations.

Ready to submit your research? Choose BMC and benefit from:

- fast, convenient online submission

- thorough peer review by experienced researchers in your field

- rapid publication on acceptance

- support for research data, including large and complex data types

- gold Open Access which fosters wider collaboration and increased citations

- maximum visibility for your research: over $100 \mathrm{M}$ website views per year

At BMC, research is always in progress.

Learn more biomedcentral.com/submissions 